\title{
Sequence Analysis of the Genome of Piscine Orthoreovirus (PRV) Associated with Heart and Skeletal Muscle Inflammation (HSMI) in Atlantic Salmon (Salmo salar)
}

\author{
Turhan Markussen ${ }^{1}$, Maria K. Dahle ${ }^{1}$, Torstein Tengs ${ }^{1}$, Marie Løvoll ${ }^{1}, \varnothing y s t e i n$ W. Finstad ${ }^{3}$, \\ Christer R. Wiik-Nielsen ${ }^{1}$, Søren Grove ${ }^{1}$, Silje Lauksund ${ }^{2}$, Børre Robertsen ${ }^{2}$, Espen Rimstad ${ }^{3 *}$ \\ 1 Department of Laboratory Services, National Veterinary Institute, Oslo, Norway, 2 Norwegian College of Fishery Science, University of Tromsø, Troms $\varnothing$, Norway, \\ 3 Department of Food Safety and Infection Biology, Norwegian School of Veterinary Science, Oslo, Norway
}

\begin{abstract}
Piscine orthoreovirus (PRV) is associated with heart- and skeletal muscle inflammation (HSMI) of farmed Atlantic salmon (Salmo salar). We have performed detailed sequence analysis of the PRV genome with focus on putative encoded proteins, compared with prototype strains from mammalian (MRV T3D)- and avian orthoreoviruses (ARV-138), and aquareovirus (GCRV-873). Amino acid identities were low for most gene segments but detailed sequence analysis showed that many protein motifs or key amino acid residues known to be central to protein function are conserved for most PRV proteins. For $M$-class proteins this included a proline residue in $\mu 2$ which, for MRV, has been shown to play a key role in both the formation and structural organization of virus inclusion bodies, and affect interferon- $\beta$ signaling and induction of myocarditis. Predicted structural similarities in the inner core-forming proteins $\lambda 1$ and $\sigma 2$ suggest a conserved core structure. In contrast, low amino acid identities in the predicted PRV surface proteins $\mu 1, \sigma 1$ and $\sigma 3$ suggested differences regarding cellular interactions between the reovirus genera. However, for $\sigma 1$, amino acid residues central for MRV binding to sialic acids, and cleavage- and myristoylation sites in $\mu 1$ required for endosomal membrane penetration during infection are partially or wholly conserved in the homologous PRV proteins. In PRV $\sigma 3$ the only conserved element found was a zinc finger motif. We provide evidence that the S1 segment encoding $\sigma 3$ also encodes a 124 aa (p13) protein, which appears to be localized to intracellular Golgi-like structures. The S2 and L2 gene segments are also potentially polycistronic, predicted to encode a 71 aa- (p8) and a 98 aa (p11) protein, respectively. It is concluded that PRV has more properties in common with orthoreoviruses than with aquareoviruses.
\end{abstract}

Citation: Markussen T, Dahle MK, Tengs T, Løvoll M, Finstad ØW, et al. (2013) Sequence Analysis of the Genome of Piscine Orthoreovirus (PRV) Associated with Heart and Skeletal Muscle Inflammation (HSMI) in Atlantic Salmon (Salmo salar). PLoS ONE 8(7): e70075. doi:10.1371/journal.pone.0070075

Editor: Pierre Boudinot, INRA, France

Received February 1, 2013; Accepted June 16, 2013; Published July 29, 2013

Copyright: (c) 2013 Markussen et al. This is an open-access article distributed under the terms of the Creative Commons Attribution License, which permits unrestricted use, distribution, and reproduction in any medium, provided the original author and source are credited.

Funding: This work was supported by the Norwegian Research Council of Norway grant nos. 186907 and 183196/S40, and the Strategic Internal Research programme no. 31002 at the National Veterinary Institute, Norway. The funders had no role in study design, data collection and analysis, decision to publish, or preparation of the manuscript.

Competing Interests: The authors have declared that no competing interests exist.

*E-mail: espen.rimstad@nvh.no

\section{Introduction}

Piscine orthoreovirus (PRV) is associated with heart and skeletal muscle inflammation (HSMI) of farmed Atlantic salmon (Salmo salar) [1]. Infectious viral diseases are prevalent in farmed fish, and HSMI is an example of an emerging disease in the intensive farming of Atlantic salmon. HSMI is usually observed 5-9 months after transfer of the fish from the freshwater stage to seawater grow out areas [2] and is characterized by inflammation of the epi-, endo- and myocard and of the red skeletal muscle. The majority of the fish in an affected cage will show lesions in the heart and the cumulative mortality may reach $20 \%$ [2]. The virus has not successfully been cultivated continuously in cell cultures, although PRV harvested from two week cultures in GF-1 cells have been used for challenge experiments [3]. The PRV genome was mapped by high-throughput pyrosequencing of material from diseased fish and found to consist of 10 dsRNA segments [1]. By the use of real time RT-PCR it has been shown that PRV is widely distributed among both farmed and wild Atlantic salmon [1,4]. The sizes of the genomic segments are distributed in the classical orthoreoviral groups L1-3, M1-3 and S1-4. The S1 and S2 segments are possibly bicistronic having accessory small putative open reading frames.

The 3 '-terminal nucleotide sequence (UCAUC-3') in the PRV gene segments is conserved and identical to both orthoreoviruses and aquareoviruses $[1,5,6]$. On the other hand, the $5^{\prime}$-terminal nucleotide sequence $\left(5^{\prime}\right.$-GAUAAA/U) of PRV is unique, as are the analogue sequences for each of the individual species within the Orthoreovirus genus (MRV, ARV, Nelson Bay, Baboon and Reptilian orthoreoviruses) and of those species in the Aquareovirus genus (Aquareovirus $\mathrm{A}$ and $\mathrm{C}$ ) for which the $5^{\prime}$-end sequences are known [5,7].

Based upon phylogenetic analysis a common evolutionary origin of the genera Aquareovirus and Orthoreovirus has been revealed [5]. Phylogenetic analyses performed separately for each PRV 
segment has shown that this virus branches off the common root of the Aquareovirus and Orthoreovirus genera which could indicate that PRV may represent a genetic new lineage, divergent from other reovirus genera [1]. To our knowledge, aquareoviruses and orthoreoviruses, with an amino acid identity of $42 \%$ in the dsRNA-dependent RNA polymerase ( $\mathrm{RdRp})$, are the only reovirus genera with identity of more than $30 \%$ in the $\operatorname{RdRp}$ that are placed in separate genera [5]. The prototype strain mammalian reovirus type 3 Dearing (MRV T3D) was chosen for comparison as this strain is the best studied within the genera. Low amino acid homologies to the MRV proteins $\lambda 1, \lambda 2, \lambda 3, \mu 1, \mu 2, \mu 3, \sigma 2$ and $\sigma N S$ are found in PRV as well as in the aquareoviruses (AqRV) [1]. AqRV have been isolated from a wide variety of aquatic animals, including molluscs, finfish and crustaceans, while the orthoreoviruses have been found in reptiles, birds and mammals. There is low sequence homology of genes and proteins between the species in genus Orthoreovirus indicating a long time divergence [6]. AqRV have 11 genomic segments while both the orthoreoviruses and PRV have 10.

Viral particles of MRV and ARV consist of a double layered protein capsid with inner and outer layers. Studies of MRV indicate that the $\sigma \mathrm{l}$ protein attaches to cell surface receptors and thus is important for the cell and tissue tropisms [8-10]. MRV particles enter the cell through receptor-mediated endocytosis. MAbs directed against the $\sigma 1$, the $\sigma 3$ and $\mu 1 \mathrm{C}$ outer capsid proteins, and the core spike protein $\lambda 2$ can neutralize MRV [11].

Following endocytosis, the outer capsid undergoes proteolysis within the acidic compartment of the endosomes, resulting in the removal of $\sigma 3$ and cleavage of $\mu 1$ to $\mu 1 \mathrm{C}$ and $\mu 1 \mathrm{~N}[12,13]$. The resulting intermediate subviral particles (ISVPs) penetrate the endosomal lipid bilayer, probably through the action of exposed hydrophobic parts of the cleaved $\mu 1$ protein [14-17]. This makes endosomal membrane penetration possible and is followed by cytoplasmic release of transcriptionally active viral cores $[18,19]$. Inside the cores, full-length capped but non-polyadenylated viral mRNAs are made. Cap formation requires the sequential activity of polynucleotide phosphohydrolase, guanylyltransferase and methyltransferase [20]. The $\lambda 1$ protein functions as helicase and triphosphatase, $\lambda 2$ as the guanylyltransferase and $\lambda 3$ is the RNA polymerase [21-25]. S-adenosyl-L-methionine (SAM) is the substrate (methyl donor) for the methylation of the type 1 cap mediated by $\lambda 2$ [24,26-29]. The transcripts act as templates for both translation and replication of viral genomic dsRNA [30].

The present study was performed to compare the properties of the putative PRV proteins to analogues of the orthoreoviruses MRV, ARV and the aquareovirus grass carp reovirus (GCRV). Through in silico analysis, 10 deduced amino acid sequences of PRV proteins were assigned. It was concluded that PRV is more related to the genus Orthoreovirus than to the Aquareovirus.

\section{Results}

\section{Genome Organization}

The PRV genome consists of 10 segments containing at least 10, but has possibly $13 \mathrm{ORFs}$ or more. The genome has a length of $23320 \mathrm{nt}$ and a GC content of $47 \%$. For both orthoreoviruses and aquareoviruses the ultimate nucleotides from each end are inverted complements [5,31-34]. The length of the 5'-UTRs was shortest for the L segments, 7-18 nucleotides, while M3 and S4 had the longest with 84 and 38 nucleotides, respectively (Figure 1). The length of the 3'-UTRs varied between 44-89 nucleotides, the longest were found in the M segments (Figure 1). Segment comparison showed that PRV 5'-UTRs were on average significantly shorter than the $3^{\prime}$-UTRs. In PRV, the three ultimate nucleotides in 5'- and $3^{\prime}$-end of each segment are inverted complements. RNA secondary structure predictions using mFold version 2.3 [35] performed at $15^{\circ} \mathrm{C}$ of the $5^{\prime}$ - and $3^{\prime}$ - UTRs of mRNA from each genomic segment was assayed using energy minimization criteria. The predictions were panhandle structures, but the last 3 '-end nucleotides were not a part of the stem structures. For segment S2, however, the prediction was not a panhandle structure (data not shown).

The PRV genome segments except for S1 and S4 were assigned according to the assignment used for MRV (Table 1). Hence, for example, the PRV segment that encodes the core protein $\lambda 2$ is called L2, although it is slightly longer than the other L segments. Based upon sequence homology to MRV and ARV in particular, eight of the deduced translation products are assumed structural proteins. For PRV, the S1, S2 and possibly L2 gene segments have additional internal open reading frames $(\mathrm{ORFs})$ in addition to the $\sigma 3, \sigma 2$ and $\lambda 2$-encoding ORFs (Table 1, Figure 1).

\section{L-class Gene Segments}

PRV gene segment $L 1$ is predicted to encode the $\lambda 3$ protein (Table 1, Figure 1). This is the virus' RNA-dependent RNA polymerase $(\mathrm{RdRp})$ responsible for viral transcription and replication. It displays the highest amino acid sequence similarity to MRV, ARV and GCRV (Table 2). Multiple sequence alignment of PRV $\lambda 3$ with the corresponding protein sequences from MRV, ARV and GCRV revealed that important polymerase motifs are also conserved in the PRV protein (Figure S1). Comparing with detailed structure-function analysis made of MRV T3D $\lambda 3$ [36], we found high conservation particularly in the catalytic core (aa 350-900), and of specific amino acids predicted to be responsible for interaction with the RNA template, NTP and the $5^{\prime}$-cap. The previously described catalytic motifs I, II, III and F1-F3 could easily be identified [37-40], including the universal RdRp GDD motif (within motif III) involved in transcriptional initiation [41-43]. The $\mathrm{N}$ - and C-terminal domains of the polymerase, predicted to be involved in interaction with the capping protein $\lambda 2$ and RNA helicase $\lambda 1$ for MRV, are somewhat less conserved. This is line with a lower sequence conservation of the other PRV $\lambda$ proteins.

PRV gene segment L2 encodes the $\lambda 2$ protein (Table 1, Figure 1). In MRV and $A R V(\lambda C)$ this is the capping enzyme, the main contributor when generating the 5 'terminal cap, on virally encoded mRNAs [24,26-29]. The MRV- and ARV proteins contain both the guanylyltransferase and methyltransferase activities necessary for the generation of this type 1 cap structure [24,27,29,44,45]. For PRV, multiple sequence alignment reveals relatively low amino acid identities to the corresponding proteins in MRV, ARV and GCRV, although key amino acid residues and important functional domains are highly conserved (Table 2, Figure S2). These include residues $\mathrm{K}_{190}$ which is essential for autoguanylation, $\mathrm{H}_{223}$ and $\mathrm{H}_{232}$ which are essential for guanylyltransferase activity and the $S$-adenosyl-L-methionine (SAM) binding pocket [44-47]. $\mathrm{K}_{171}$, a significant but not essential contributor for autoguanylation [46], is not conserved in PRV at this position although a KY motif sits just two positions downstream. A region containing an ATP/GTP binding site in the MRV protein [45] is also highly conserved in all four homologues proteins. Also, a hypersensitive cleavage site has been identified when using recombinant $\mathrm{MRV} \lambda 2$ and $\mathrm{ARV} \lambda \mathrm{C}$ $[44,46]$. In the PRV protein, the two amino acids on either side of this cleavage site are identical to those in ARV. Secondary structure predictions using PSIPRED v3.0 $[48,49]$ suggests that this site resides in a predicted random coil region shortly after a predicted strand region, perhaps constituting an exposed region 


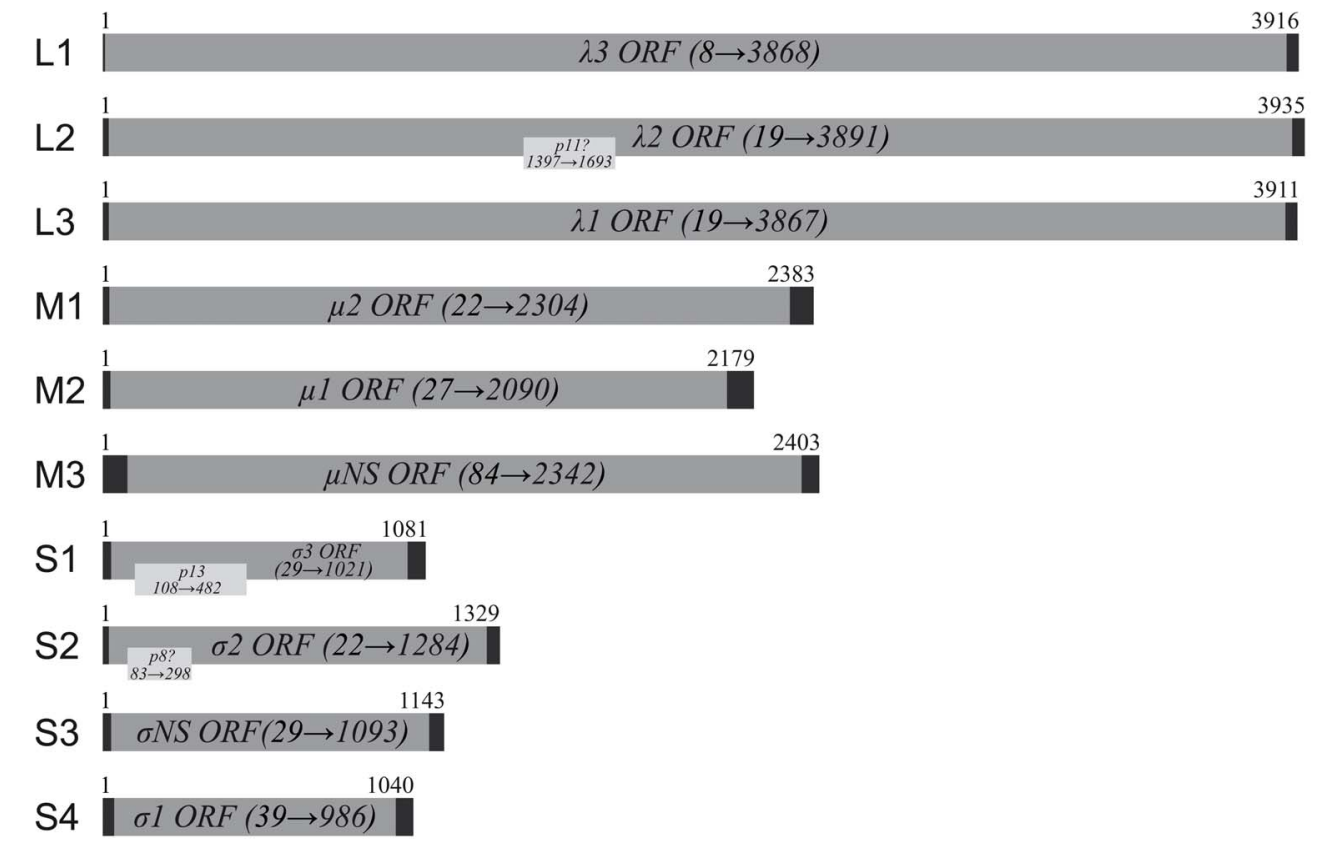

Figure 1. The PRV genome. Gene segments are assigned according to mammalian reoviruses. Open reading frames (ORFs) and putative encoded proteins are indicated by regions in grey, with start and end positions indicated. Non-translated regions (UTR's) at gene segment ends are shown in black. Gene segments L2, S1 and S2 are possibly polycistronic.

doi:10.1371/journal.pone.0070075.g001

highly susceptible to cleavage by cellular proteases (not shown). Additionally, the L2 gene segment may be polycistronic (Table 1, Figure 1).

PRV gene segment $L 3$ is predicted to encode the $\lambda 1$ protein (Table 1, Figure 1). This is the core capsid shell homologue of MRV $\lambda 1$, ARV $\lambda$ A and GCRV VP3 [50-52]. Multiple sequence alignment showed higher amino acid identities between PRV and the three prototype strains than observed for $\lambda 2$ but lower than for $\lambda 3$ (Table 2, Figure S3). Key functional residues or domains are conserved in PRV $\lambda 1$. A CCHH zincfinger motif in particular, conserved in the MRV, ARV and GCRV proteins and shown to bind zinc in core crystal structure analysis [51,53,54], is also conserved in PRV $\lambda 1$ (Figure S3). For $\mathrm{MRV}$, the $\sim 500$ residue $\mathrm{N}$-terminal region has been shown to exhibit triphosphate phosphohydrolase (NTPase), helicase, and RNA triphosphatase activities while the $\sim 200$ residue $\mathrm{N}$-terminal parts, a region predominantly hydrophilic, is assumed to be responsible for the dsRNA binding property of $\lambda 1[21,23,52,55-$ 58]. For PRV, as for the homologous proteins from the selected reovirus prototypes, a predominantly N-terminal RNA/DNA binding region was predicted using BindN [59] (data not shown).

\section{M-class Gene Segments}

PRV gene segment M1 encodes the $\boldsymbol{\mu} 2$ protein (Table 1, Figure 1). Compared to the proteins encoded by the L-class gene segments, PRV $\mu 2$ has a lower amino acid sequence identity with the homologous proteins in the MRV, ARV and GCRV (Table 2, Figure S4). In MRV, $\mu 2$ is a minor structural protein, binds both ssRNA and dsRNA independent of sequence, and possibly acts as a co-factor or subunit of the viral RNA polymerase [30,60,61]. In addition, both MRV $\mu 2$ and ARV $\mu \mathrm{A}$ display NTPase- and RTPase activities [62-64]. In MRV $\mu 2$, the two lysines $\mathrm{K}_{415}$ and $\mathrm{K}_{419}$ in the region $\mathrm{A}_{411}$ VLPKGSFKS $\mathrm{V}_{420}$, have been shown to be essential for NTPase activity [63]. Both these lysines are conserved in all four homologous proteins (Figure S4).
A second putative nucleotide binding motif, $\mathrm{D}_{446} \mathrm{EVG}_{449}$ [65], is only partially conserved. The $\mathrm{P}_{208}$ in MRV T3D has also recently been shown to be a determinant of type I IFN antagonism and a modulator of induction of myocarditis in neonatal mice [69]. $\mathrm{P}_{208}$ is conserved in all four proteins.

PRV gene segment M2 encodes the $\mu 1$ protein (Table 1, Figure 1). This is the homologue of the major outer capsid protein of MRV [54,70,71]. In ARV and GCRV the homologous proteins are called $\mu \mathrm{B}$ and $\mathrm{VP} 4$, respectively [5,50]. The highest amino acid sequence identity was found towards the homologous proteins in MRV and ARV, somewhat lower for GCRV (Table 2). Multiple sequence alignment showed that the $\mathrm{N}$ terminal sequence parts of the four proteins display higher conservation compared to the rest of the protein (Figure S5). A post-translational autolytic cleavage site in the MRV protein between $\mathrm{N}_{42}$ and $\mathrm{P}_{43}$, which produces a small $\mathrm{N}$-terminal- $(\mu 1 \mathrm{~N})$ and a larger C-terminal fragment $(\mu 1 \mathrm{C})$, required for $\mathrm{MRV}$ endosomal membrane penetration and infection, is conserved in all four proteins [70,71]. The cleavage of MRV $\mu 1$ during infection is dependent upon $\mathrm{N}$-myristoylation at $\mathrm{G}_{2}$, as well as binding to the $\mathrm{S} 1$ gene product $\sigma 3$ (see below) [72]. Similarly, $\mathrm{ARV} \mu \mathrm{B}$ is also myristoylated at $\mathrm{G}_{2}$ and post-translationally cleaved, with $\mu \mathrm{B}$ and its cleavage product $\mu \mathrm{BC}$ associating with $\sigma \mathrm{B}$ $[68,73]$. The $\mathrm{G}_{2}$-residue is conserved in all four proteins (Figure S5). These two processes, myristoylation and cleavage, are believed to be crucial for membrane penetration with $\mu 1 \mathrm{~N}$ as the principal mediator $[17,74,75]$ (see Figure S5 legends for more details).

PRV gene segment M3 encodes the non-structural $\mu \mathrm{NS}$ protein (Table 1, Figure 1). This is the homologous counterpart of MRV and ARV $\mu$ NS [50,76,77]. The ARV $\mu$ NS protein is significantly shorter compared to the MRV protein, a difference which has been attributed to deletions (Figure S6) [78]. In GCRV, the homologous protein is NS80, the product of gene segment 4 [5]. A very low amino acid sequence identity is observed 


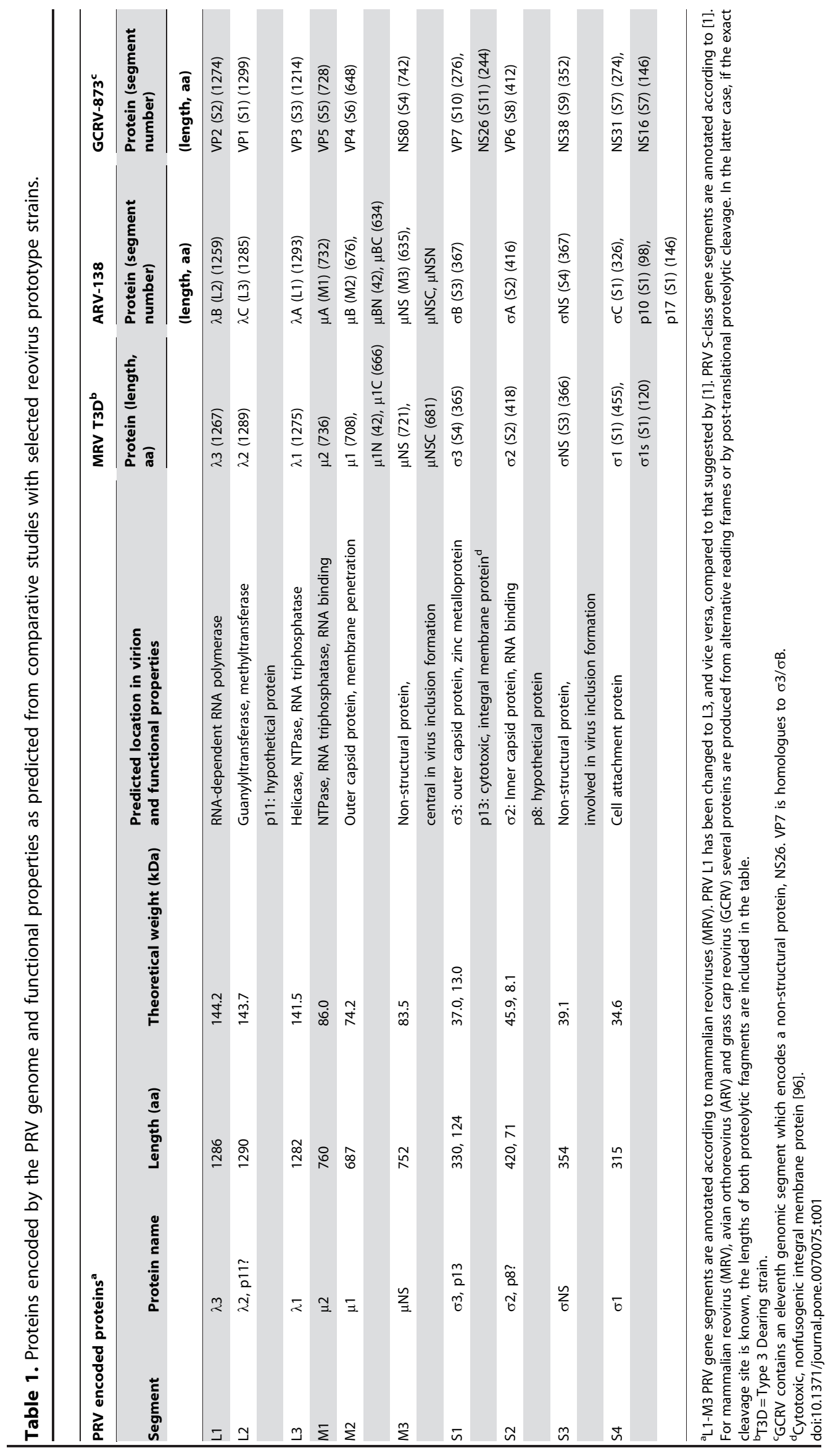


Table 2. Percentage amino acid identity among all ungapped positions between pairs; predicted PRV proteins and the homologues proteins from three reovirus prototype strains.

\begin{tabular}{|c|c|c|c|c|c|c|c|c|c|c|}
\hline & \multirow{2}{*}{$\frac{\text { PRV }}{\lambda 3}$} & \multirow{2}{*}{$\frac{\text { PRV }}{\lambda 2}$} & \multirow{2}{*}{$\frac{\text { PRV }}{\lambda 1}$} & \multirow{2}{*}{$\frac{\mathbf{P R V}}{\mu \mathbf{2}}$} & \multirow{2}{*}{$\frac{\mathbf{P R V}}{\mu \mathbf{1}}$} & \multirow{2}{*}{$\frac{\text { PRV }}{\mu \text { NS }}$} & \multirow{2}{*}{$\frac{\text { PRV }}{\sigma 3}$} & \multirow{2}{*}{$\frac{\text { PRV }}{\sigma 2}$} & \multirow{2}{*}{$\frac{\text { PRV }}{\text { oNS }}$} & \multirow{2}{*}{$\frac{P R V}{\sigma 1}$} \\
\hline & & & & & & & & & & \\
\hline MRV T3D ${ }^{a}$ & 43 & 23 & 32 & 20 & 28 & 17 & 13 & 20 & 20 & $21^{d}$ \\
\hline$A R V-138^{b}$ & 44 & 22 & 31 & 21 & 27 & 17 & 15 & 20 & 18 & 14 \\
\hline GCRV-873 & 38 & 25 & 31 & 21 & 24 & 13 & 15 & 17 & 13 & $f_{-}$ \\
\hline
\end{tabular}

between the PRV protein and the homologous proteins of the three prototype strains (13-17\%) (Table 2). Regions containing some level of conservation can though be identified (see Figure S6 legends for more details). One such motif, $\mathrm{L}_{711} \mathrm{IDFS}_{715}$, towards the C-terminal end and shown for MRV to be required for the recruitment of clathrin to viral factories [79], is partially conserved in the ARV- and PRV proteins. MRV $\mu \mathrm{NS}$, ARV $\mu \mathrm{NS}$ and GCRV NS80 have all been predicted to contain two $\alpha$-helical coiled coils regions in their C-terminal region, which have been shown to be necessary for inclusion formation [86-90]. PRV $\mu \mathrm{NS}$ also contains high $\alpha$-helical content in the C-terminal region and MultiCoil does predict coiled coil formation here although with significant lower probability compared to the MRV-, ARV- and GCRV proteins (not shown).

For both MRV and ARV M3, two products have been reported, the $\mu \mathrm{NS}$ protein representing the full-length isoform. For MRV, the second isoform $\mu \mathrm{NSC}(75 \mathrm{kDa})$ is most likely generated from the second in-frame AUG $\left(\mathrm{Met}_{41}\right)[88,91]$. In ARV, posttranslational cleavage near the $\mathrm{N}$-terminal region creates $\mu \mathrm{NSN}$ [92]. PRV $\mu$ NS does not contain a $\mathrm{Met}_{41}$, but it does contain a $\mathrm{Met}_{57}$, which is also present in MRV (Figure S6). Neither the MRV- nor PRV AUG codons encoding Met $_{57}$ comply with the Kozak rule, while the initiation codon for MRV Met 41 complies partially [93].

\section{S-class Gene Segments}

PRV gene segment $S 1$ encodes the major outer capsid protein $\sigma 3$ (Table 1, Figure 1). In MRV, ARV and GCRV the major outer capsid proteins are encoded by gene segment $\mathrm{S} 4$ $(\sigma 3), \mathrm{S} 3(\sigma \mathrm{B})$ and segment $10(\mathrm{VP} 7)$, respectively $[5,76,77,94,95]$. PRV $\sigma 3$ was recently determined to be encoded by the second smallest S-class gene segment [96]. Although amino acid identities between the PRV protein and that of the reovirus prototype strains used are very low and in the range of non-related proteins (Table 2), a Zn-finger motif is evolutionary conserved in all four proteins (Figure S7) [96,97]. Expression of $\sigma 3$ in mammalian VERO cells at $37^{\circ} \mathrm{C}$ and salmonid CHSE cells at $20^{\circ} \mathrm{C}$ demonstrated that the protein was primarily cytoplasmic. In CHSE cells, green fluorescence was observed diffusely throughout the cytoplasm while in VERO cells the protein seemed to form large inclusions (Figures 2a, b).

PRV gene segment $S 2$ encodes the core clamp protein $\boldsymbol{\sigma} 2$ (Table 1, Figure 1). In MRV, ARV and GCRV the homologues proteins are $\sigma 2, \sigma \mathrm{A}$ and $\mathrm{VP} 6$, respectively $[5,54,76,77,98,99]$. PRV S2 is the largest S-class gene segment, and possibly bicistronic (Table 1, Figure 1). Multiple sequence alignment of the four $\sigma 2 / \sigma \mathrm{A} / \mathrm{VP} 6$ proteins show overall low amino acid identities (Table 2, Figure S8). Still, between MRV cores and ARV $\sigma \mathrm{A}$ (sharing 29\% amino acid identity), comparisons of crystal structure data have shown a highly similar overall topology, including higher $\alpha$-helical content in their C-terminal regions [54,100-102]. For PRV $\sigma 2$, PSIPRED [48,49] also predicts a high $\alpha$-helical content in its $\mathrm{C}$-terminal region (Figure 3). In fact, comparing the predicted secondary structure profiles between all four reovirus proteins reveals a remarkable conservation of secondary structure (Figure 3), providing strong support that this gene segment encodes $\sigma 2$. In further support for the correct annotation of PRV $\sigma 2$, the predicted $\mathrm{pI}$ of the PRV protein is close to that of the MRV- and ARV proteins [96].

PRV gene segment $S 3$ encodes the non-structural $\sigma N S$ protein (Table 1, Figure 1). In MRV and ARV, $\sigma N S$ is encoded by gene segment $\mathrm{S} 3$ and $\mathrm{S} 4$ respectively, while in GCRV the homologues protein, NS38, is encoded by segment 9 $[5,50,103]$. Similar to the three prototype strains, PRV S3 also contains a single ORF, encoding a protein with size close to that of $\sigma$ NS/NS38 (Table 1, Figure 1). Multiple sequence alignment with these four protein sequences reveals overall very low amino acid sequence identities, not only to the PRV protein but between the three prototype strains as well (Table 2, Figure S9). In addition, PSIPRED suggests some level of protein structure conservation between PRV $\sigma \mathrm{NS}$ and the proteins from the three prototype strains (not shown). Furthermore, the predicted $\mathrm{pI}$ of the putative PRV $\sigma \mathrm{NS}$ protein shows generally more closeness to the homologous proteins in MRV, ARV and GCRV compared to the other three major PRV S-class proteins [96]. Taken together this suggests that a correct assignment of PRV $\sigma \mathrm{NS}$ has been made.

MRV $\sigma \mathrm{NS}$ has been detected in both the nucleus and cytoplasm of infected and transfected cells, with the former being linked to its nucleic acid binding capability [85,103,104]. PSORTII does not predict the presence of nuclear localization signals in the PRV protein (not shown). But, within regions of the alignment displaying somewhat higher level of conservation, NetNES 1.1 [105] does predict the presence of NESs in all four proteins (Figure S9).

The major gene product of PRV gene segment $S 4$ is the $\sigma 1$ cell-attachment protein (Table 1, Figure 1). In MRV and $\mathrm{ARV}$, the cell attachment proteins $\sigma \mathrm{l}$ and $\sigma \mathrm{C}$ are the major gene products from the bicistronic and tricistronic $\mathrm{S} 1$ gene segments, respectively [10,106-109] (Table 1). The aquareovirus GCRV does not seem to encode a homologue of the orthoreovirus cell attachment proteins [99,110]. Rather, GCRV gene segment 7 encodes two non-structural proteins (Table 1) [5].

Multiple sequence alignment with PRV $\sigma 1$ and MRV $\sigma 1 / \mathrm{ARV}$ $\sigma \mathrm{C}$ shows amino acid identities in the range of $14-21 \%$, 

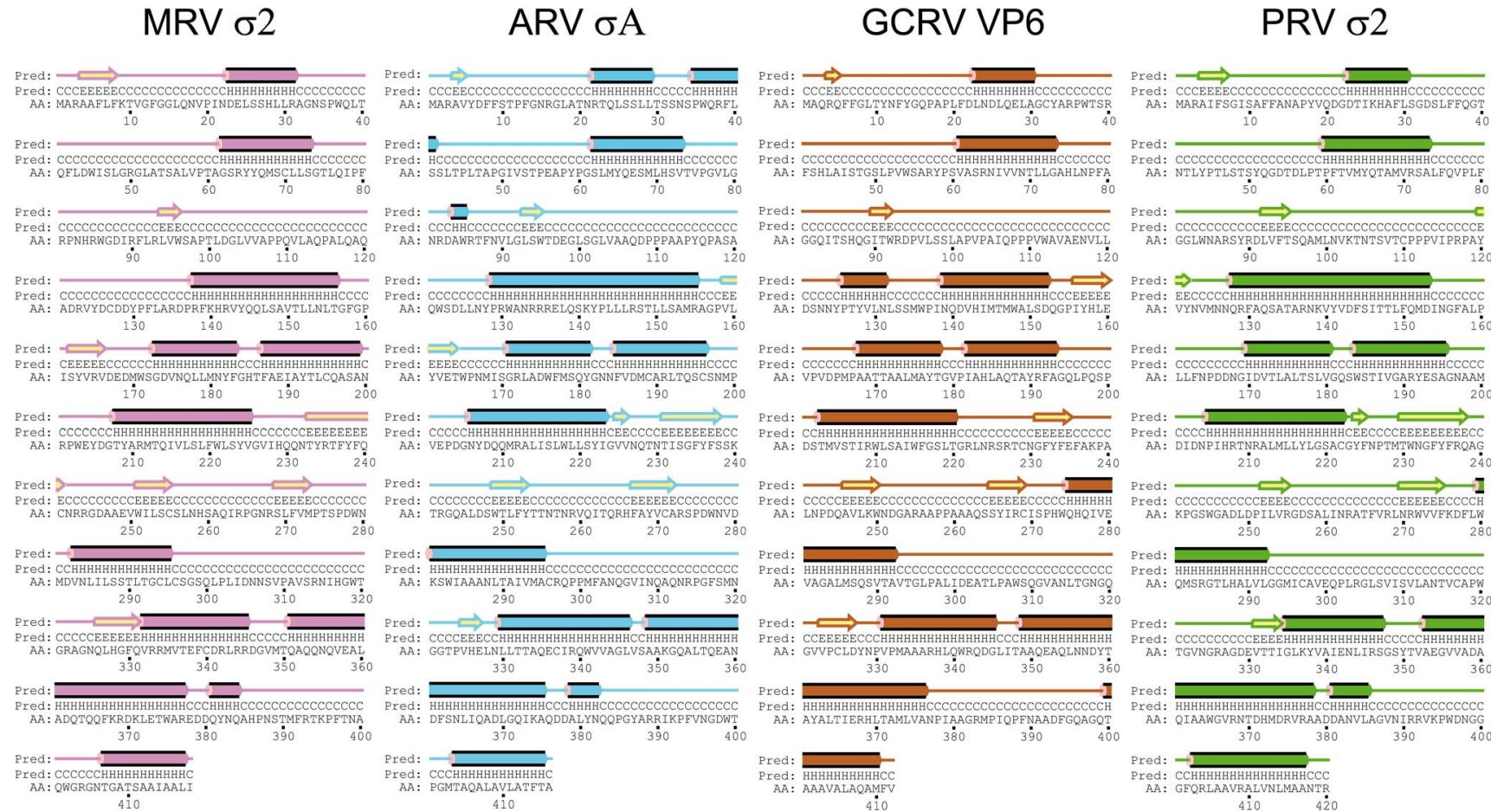

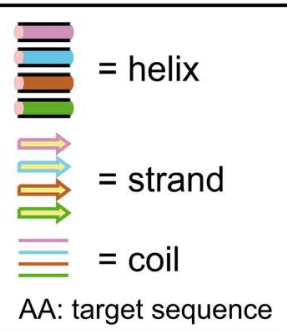

Figure 2. Expression and subcellular localization of the S1-encoded $\sigma 3$ and p13 proteins in mammalian VERO and salmonid CHSE cells. Immunofluorescent staining of $\sigma 3$ or p13 (green colour), and staining with the trans-Golgi marker WGA (red colour). Transfected VERO cells (A) and CHSE cells (B) expressing both $\sigma 3$ and p13 from the large S1 ORF (upper panels), and p13 expression from the S1 internal ORF (lower panels). Nuclei are stained with DAPI (blue colour). Yellow colour indicates colocalization of p13 and WGA. Non-transfected cells stained with WGA and antip13 serum was used as controls (CTRL).

doi:10.1371/journal.pone.0070075.g002

depending on the degree of manual adjustment of the alignment (Table 2, Figure 4; only PRV and MRV aligned). Annotation of PRV $\sigma 1$, based on the high probability presence of predicted $\alpha$ helical coiled-coil structure(s) in the $\mathrm{N}$-terminal region of the protein, was recently determined to be similar to that of MRV $\sigma 1$ and ARV $\sigma$ C (Figure S10) [96,111-114]. Secondary structure predictions using PSIPRED provides additional support for a PRV $\sigma 1 \mathrm{~N}$-terminal region dominated by $\alpha$-helixes (not shown). For the GCRV NS31 protein, on the other hand, predicted secondary structure profiles are very different from that of the three other proteins (not shown), with no predicted coil structures (Figure S10).

The MRV $\sigma$ l protein can broadly be divided into three distinct domains, the N-terminal tail which partially inserts into the virion, the body which contains the region that binds to sialic acids, and the $\mathrm{G}$-terminal head domain, which binds the receptor junctional adhesion-molecule-A (JAM-A) [115-119]. For the MRV T3D strain, $\sigma 1$ binds to $\alpha$-linked sialic acids $[120,121]$. Sequence- and structure analyses of MRV variants have indicated that amino acids in positions $198,202-205$ are involved in binding to sialic acids [122-124]. The alignment in Figure 4 suggests that several of these MRV $\sigma \mathrm{l}$ residues may be conserved in PRV, but not in the ARV protein (not shown). In fact, these residues are less conserved in the MRV T1L and T2J serotypes compared to PRV $\sigma \mathrm{l}$ (not shown). Finally, the predicted isoelectric point $(\mathrm{pI})$ for this putative PRV protein lies in the acidic range, as do MRV $\sigma \mathrm{l}$ and ARV $\sigma \mathrm{C}$ [96]. All together, we provide additional support that this protein, encoded by the smallest PRV S-class gene segment, is the cell attachment protein homologous to those of other orthoreoviruses.

\section{Accessory ORFs}

$\mathrm{PRV}$ gene segment $\mathrm{S} 1$ is bicistronic and has an internal ORF encoding a 124 aa protein (p13) (Table 1, Figure 1). This protein is expressed from the $\sigma 3$ ORF when transfected in VERO and CHSE cells, as determined by immunofluorescent staining using anti-p13 serum, where it colocalizes with the trans-Golgi marker WGA (Figures 2a, b). Colocalization of p13 with this marker was also seen following transfection with an expression plasmid containing only the p13 ORF (Figures 2a, b). The p13 
A)
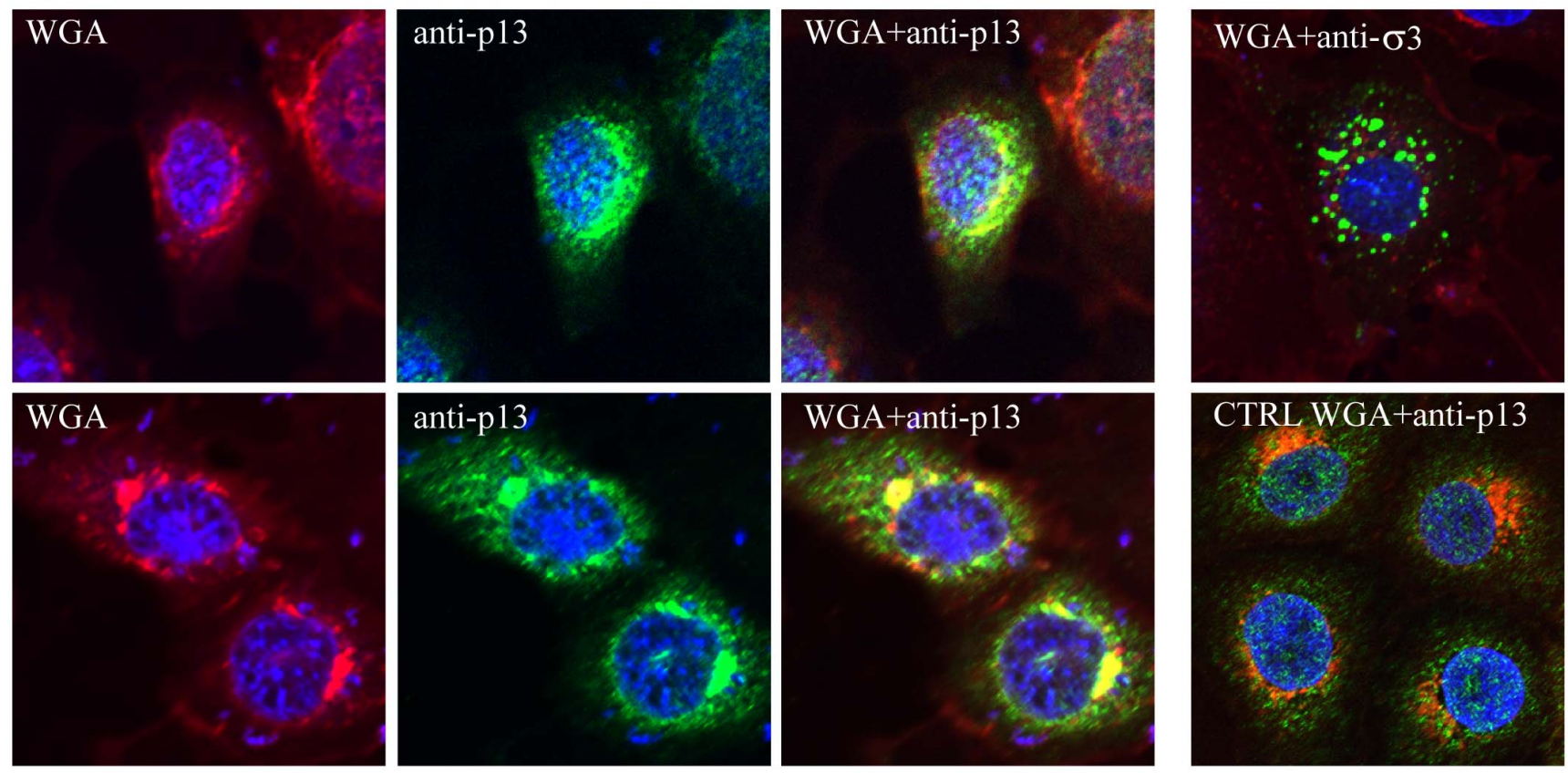

B)
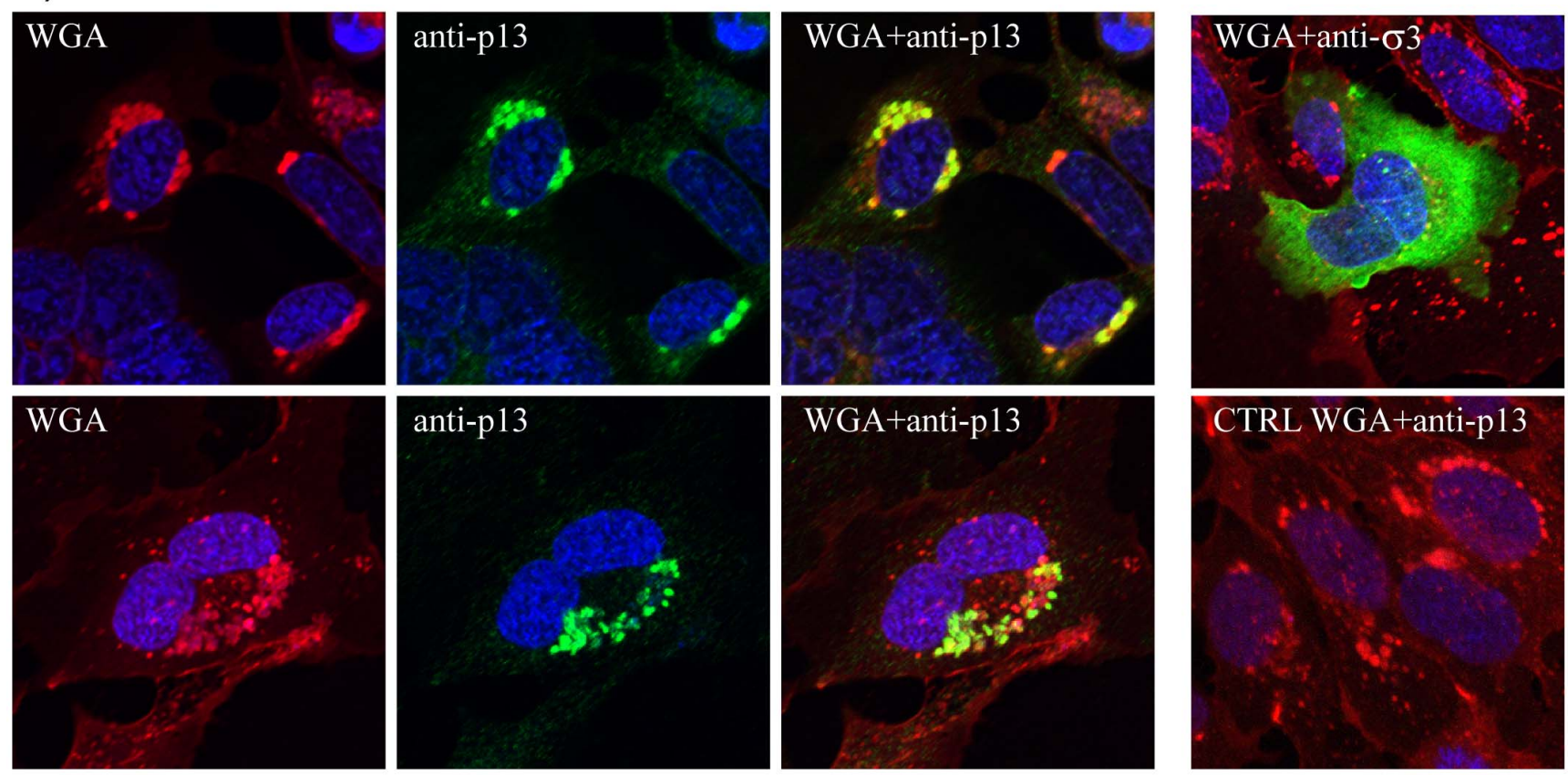

Figure 3. PSIPRED secondary structure predictions of PRV $\sigma 2$ (green) and the homologous proteins from the reovirus prototype strains MRV T3D ( $\sigma 2$, pink), ARV-138 ( $\sigma$ A, blue) and GCRV-873 (VP6, brown).

doi:10.1371/journal.pone.0070075.g003

protein was originally assumed to be a fusion-associated small transmembrane (FAST) protein capable of inducing cell-cell fusion and syncytium formation, but was recently determined to encode a nonfusogenic integral membrane protein with cytotoxic properties $[1,96]$. Scanning the PRV genome for potential accessory ORFs revealed several potential candidates. Both S2 and L2 are putative polycistronic gene segments, where the former has the potential to encode a second 71 aa hypothetical protein (p8) and the latter contains several smaller ORFs with AUG- or non-canonical
GUG/CUG start codons that could encode hypothetical proteins of sizes ranging from 55 to 135 aa. The possibility of translation initiation from non-canonical start codons should not be excluded, as has been shown for the AtSRV p22 protein which is produced from a noncanonical CUG translation start codon in segment 7 [125]. Besides the $\lambda 2$-encoding ORF, the largest L2 ORF containing an AUG translation initiation codon could encode a small protein of 98 aa (p11) (Table 1, Figure 1). None of these putative gene products display any apparent sequence similarities 


\section{б1 alignment}

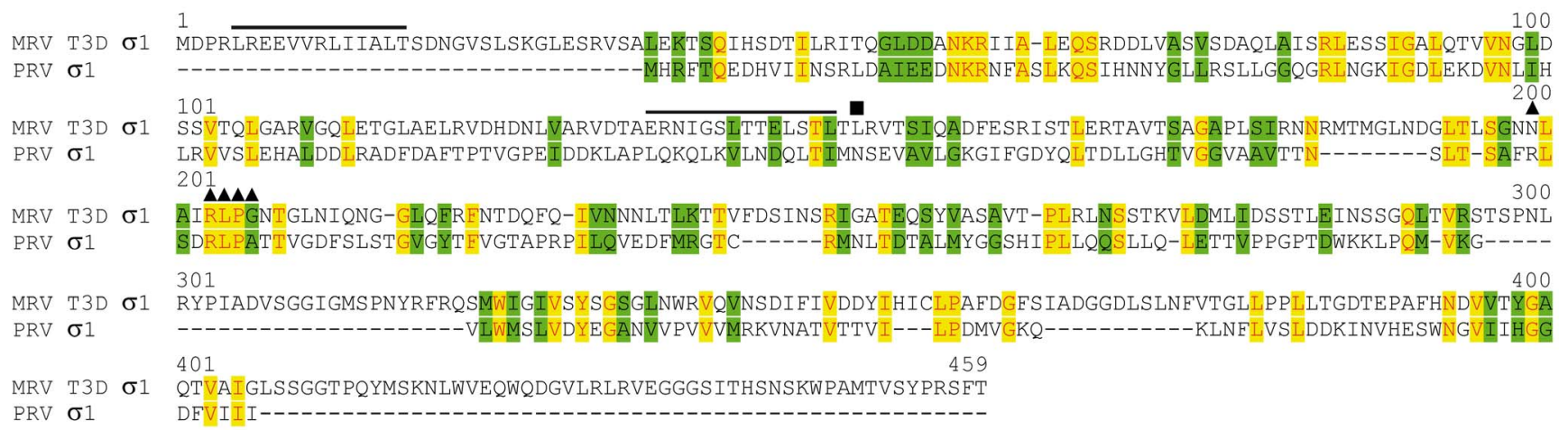

Figure 4. Multiple sequence alignment of PRV $\sigma 1$ with MRV T3D $\sigma 1$. Black lines represent putative nuclear export signals (NEP) in MRV and PRV, respectively, as predicted by NetNes 1.1. $\mathbf{\square}=\mathrm{L}_{149}$ in the MRV protein involved in a second predicted NES. $\boldsymbol{\Lambda}=$ residues in the MRV protein involved in binding to sialic acid residues. The alignment has been manually adjusted. doi:10.1371/journal.pone.0070075.g004

towards the additional gene products from MRV S1 $(\sigma 1 \mathrm{~s}), \mathrm{ARV}$ S1 (p10, p17) or GCRV segment 7 (NS16) (not shown). ARV p10 and GCRV NS16 have been shown to be FAST proteins capable of inducing cell-cell fusion and syncytium formation [126,127]. No sequence similarities to other known reovirus FAST proteins, such as Atlantic salmon reovirus (AtSRV p22), Turbot reovirus (SMReV p22), Baboon reovirus (BRV p15), Reptilian reovirus (RRV pl4), Broome virus (BroV pl3) and Nelson Bay reovirus (NBV p10) was observed either (not shown) [7,125,127-130]. Low or absence of sequence similarities at the primary amino acid sequence level is though a common trait among reovirus FAST proteins [131]. ProtScale hydrophobicity plots does indicate the presence of structural motifs in both these hypothetical proteins characteristic of FAST proteins (transmembrane domain (TMD), hydrophobic patch $(\mathrm{HP})$, basic region $(\mathrm{PB}))$, with patterns similar to ARV p10, and less similar to GCRV NS16 [127,131] (Figure S11). The polybasic region is though shorter and less defined in the PRV proteins. Still, both are predominantly hydrophobic and have high predicted pI's of 8,81 (p8) and 9,38 (p11) which is similar to that of other known FAST proteins (8.80-9.84). Also, the AUG translation initiation codon in the p8 gene complies with Kozak [93]. In contrast, the pl 1 AUG translation initiation codon deviates from Kozak in all positions. The present study may provide an example of deviations from Kozak consensus, as the AUG translation initiation codon in the PRV p13 ORF deviates from Kozak consensus both at positions -3 and +4 . All known FAST proteins are also modified either by palmitoylation or myristoylation [127]. No myristoylation- or S-palmitoylation sites were predicted for the hypothetical p8 protein. In contrast, Spalmitoylation sites were predicted for $\mathrm{pll}$, at $\mathrm{C}_{13}$ and $\mathrm{C}_{14}$. Assuming a $\mathrm{N}_{\text {exo }} / \mathrm{C}_{\mathrm{cyt}}$ surface membrane topology for pl1, the location of these sites differ from the S-palmitoylation sites in ARV- and NBV p10, which are located between their transmembrane and polybasic regions (Figure S11) [127]. Also, reovirus FAST proteins may contain N-glycosylation signals in their sequence $[129,130]$. Two potential N-glycosylation sites were predicted in $\mathrm{p} 11$, at position 8 and 66 . None were predicted in $\mathrm{p} 8$. A distinct polyproline motif, common in some reovirus FAST proteins, was not present in $\mathrm{p} 8$ and $\mathrm{p} 11$. However, in the latter, although not clustered together, there are three proline residues towards the C-terminal end of which two flank the basic region.

Whether either of these two putative PRV proteins are homologues to other known reovirus FAST proteins or not, information which would enable a better classification of PRV, will require further experimental investigations. It should though be noted that syncytia are not common histopathological findings in HSMI diseased fish [2], which would suggest that PRV is nonfusogenic. Therefore, the possibility that the hypothetical accessory PRV proteins display functional properties similar to the $\sigma \mathrm{ls}$ and p17 proteins encoded by the bicistronic genes in MRV and ARV, respectively, should be considered.

\section{Discussion}

In the present study we have performed detailed comparative sequence analysis of the non-translated (UTR) regions and the putative proteins encoded by the PRV genome to prototype strains from mammalian and avian orthoreoviruses, and one aquareovirus. The results suggest that the PRV genome encodes at least 10 proteins, but it may also contain up to 13 or more ORFs.

In general, amino acid identities between PRV and the three prototype strains were low for most gene segments, highest for the L-class gene segment encoding the RdRp. Functional constraints often cause viral core proteins to remain more conserved than the outer capsid proteins, as illustrated by the conserved structural motifs predicted for PRV proteins $\lambda 1$ and $\sigma 2$. In the latter case, a remarkable strong conservation of protein secondary structure across genus lines of orthoreoviruses and aquareoviruses, was predicted. This illustrates conservation of secondary structure over primary sequence, reflecting the importance of structural features for function(s), where even minor alterations would be deleterious. Furthermore, residues important for the enzymatic actions of reovirus proteins are to a larger extent more conserved than other residues, as exemplified by the PRV $\lambda 3$ and $\lambda 2$ proteins. Examples of conserved amino acid residues include the two lysines essential for the NTPase activity of $\mu 2$ [63] and the post-translational autolytic cleavage- and myristoylation sites in $\mu 1[68,70,71,73]$. The latter strongly suggests that analogues mechanisms are involved in membrane penetration by this PRV protein as in orthoreo- and aquareoviruses. The amino acid identities between PRV and the prototype strains for the $\mu \mathrm{NS}, \sigma 1$ and $\sigma 3$ proteins were very low or similar to that of non-related proteins $(<20 \%)$ [31]. Sequence analysis did, though, reveal protein motifs or key amino acid residues linked to important protein functions are conserved also in PRV, particularly to those of MRV and ARV. 
For the $\mu \mathrm{NS}$ proteins (NS80 in GCRV), the limited sequence similarities may be linked to its multifunctionality. Together with $\sigma \mathrm{NS}$ (NS38 in GCRV) they are central in recruitment of core proteins and forming viral factories, sequence independent binding of ssRNA, and vital in RNA packaging and replication $[66,67,68,80-87,103,132]$. Virus proteins that make up the core have evolved over time due to selection pressures and thus the resulting rate of change in multifunctional proteins would be higher by comparison, resulting in only rudimentary similarities being left at the primary sequence level, although important structural features may be more conserved. Whether the PRV $\mu \mathrm{NS}$ gene also produces two gene products as the MRV protein does, or whether post-translational cleavage is involved as in ARV $\mu \mathrm{NS}$, could not be determined from sequence information alone.

Several proteins encoded by reoviruses have been shown, or are suggested, to exhibit type I IFN antagonistic properties, including MRV $\mu 2$, ARV $\sigma \mathrm{A}$ and MRV $\sigma 3$ [133-137]. A previously established reporter gene system [138] was used to investigate whether expression of PRV $\mu 2, \sigma 2$ and $\sigma 3$ could have an antagonistic effect on the type I IFN response in a salmonid cell line (not shown). The reporter constructs use a salmon minimal type I IFN (IFNal) promotor [139] and an interferon-stimulated response element (ISRE)-reporter (Agilent technologies). Transfection method and activation of type I IFN response was performed as previously described $[138,139]$. No effect could be detected by any of the three viral proteins, neither on IFNal- or ISRE induction.

The monocistronic $\mathrm{S} 4$ gene segment was determined to encode the PRV cell attachment protein $\sigma$, the finding supported by predicted pI's but more importantly, by structural motifs common to both MRV $\sigma \mathrm{l}$ and ARV $\sigma \mathrm{C}$, as was recently also described by others [96]. Several amino acid residues in MRV $\sigma$ l shown to bind to sialic acids may also be conserved in the PRV protein, which might suggest that PRV utilizes a receptor mediated uptake mechanism involving similar but not identical sialic acid structures.

PRV $\sigma 3$ expression in mammalian VERO cells at $37^{\circ} \mathrm{C}$ and in salmonid CHSE cells at $20^{\circ} \mathrm{C}$ showed a predominantly cytoplasmic localization, although the staining pattern differed in the two cell lines. The punctuated staining pattern observed in the VERO cells may be linked to aberrant folding of the protein at the higher temperature.

FAST proteins have been reported from the Orthoreovirus and Aquareovirus genera [131]. In contrast to fusogenic reoviruses, for which syncytia are commonly registered, syncytia are not common histopathological findings in HSMI diseased fish [2]. Sequence data alone was not sufficient to determine whether the putative p8, p11 or p13 could be a FAST protein. All three proteins contained predicted properties or motifs only partially consistent with FAST proteins. Recently, using an avian cell line cultivated at $37^{\circ} \mathrm{C}$, it was shown that p13 is a cytotoxic protein binding to intracellular membranes, and not a FAST protein [96]. Our findings supported this, and we show that p13 was produced from the internal ORF in the $\sigma 3$ coding sequence, in both VERO- and the CHSE cells, where it colocalizes with a marker for the trans-Golgi network. The colocalization of p13 and this marker was further supported by the transfection assays using an expression plasmid construct containing the p13 ORF only. Transfection studies with expression plasmid constructs containing the p13 ORF performed in both VERO and CHSE cells have failed to induce cell-cell fusion (data not shown). Transfection with expression plasmid constructs containing the putative p8 and p1l ORFs were not performed. The absence of observed fusogenic activity of PRV and lack of induced syncytia after cellular expression of p13 may indicate that
PRV is not fusogenic, as also recently described for p13 [96]. It should not be excluded though that efficient cell-cell fusion is dependent upon a second coexpressed PRV protein, as seen for the GGRV NS16 whose activity is enhanced following coexpression with NS26 [126]. Also, it should be considered whether p13 is a functional equivalent to the MRV $\sigma$ ls or ARV p17 proteins. Here, $\sigma$ ls has been shown to have a key role in hematogenous dissemination of the virus $[140,141]$, involved in reovirus-induced apoptosis [142] and in $\mathrm{G}(2) / \mathrm{M}$ cell cycle arrest [143]. ARV p17 has also been shown to be involved in $\mathrm{G}(2) / \mathrm{M}$ cell cycle arrest and shutoff of host protein translation [144] and also acts as a nucleocytoplasmic shuttling protein $[108,127,145]$. Further studies are warranted in order to elucidate the function of p13 and the putative proteins encoded by the internal S2- and L2 ORFs regarding their potential functional properties.

For members of the Reoviridae more than 30\% amino acid sequence identity of the $\mathrm{RdRp}$ is used as indicative of genus affiliation. But there are exceptions to this, the Rotavirus B polymerase is only $22 \%$ identical to other rotaviruses [5]. Sequence alignment of the PRV $\lambda 3$ protein showed several conserved polymerase motifs, and the identities to the RdRps of the orthoreoviruses $\mathrm{MRV}$ and $\mathrm{ARV}$, and the aquareovirus GCRV, were well above the $30 \%$ limit. However, the amino acid sequence identities between the RdRps from the orthoreoviruses MRV, ARV and the aquareovirus GCRV is above $40 \%$ (not shown), which disqualifies the use of this quantitative taxonomic criterion to distinguish between these genera. However, there are differences between orthoreoviruses and aquareoviruses that justify to keep them as separate genera, as listed by Attoui and co-workers [5], like distinct econiches, 10 versus 11 segments, the GC-content of orthoreoviruses is $44-48 \%$ while that of aquareoviruses is $52-$ $60 \%$, many orthoreoviruses do not induce syncytia in contrast to the majority of known aquareoviruses, and there is no antigenic relationship between them. Of these criterions PRV has the following in common with the orthoreoviruses: 10 dsRNA segments, $47 \%$ GC-content, syncytia is not reported as a common histopathological finding, nor in cell culture where virus isolation has been attempted (personal observation). The only common criterion with aquareoviruses is the econiche, if fish consisting of a large number of heterogenous species from very different environments should be regarded as a single econiche. The antigenic relationships are unknown.

PRV is not the first reovirus with 10 genomic segments that has been described from fish. A virus isolated in Thailand from the striped snakehead fish (Ophicephalus striatus, also known as Channa striata) with epizootic ulcerative syndrome, was also found to contain 10 genomic segments [146]. However, no nucleotide sequences are available for this virus. The lack of serological crossneutralization activity to other $\mathrm{AqRV}$, and the difference in number of gene segments made the authors conclude that the virus was not a member of the Aquareovirus genus.

To conclude, although it probably is many million years since the most recent common ancestor for PRV and orthoreo- and aquareoviruses existed, we found conserved structural motifs and somewhat less conserved sequence motifs for all 10 PRV genomic segments. All together, the PRV has more properties in common with the Orthoreovirus genus than with the Aquareovirus and should hence be renamed Piscine orthoreovirus.

\section{Materials and Methods}

\section{Computer Analyses}

GenBank accession numbers for all PRV, MRV T3D, ARV138 and GCRV-873 sequences used in the present study is shown 
in Table S1. Multiple sequence alignments of protein sequences were performed in AlignX (Vector NTI Advance ${ }^{\mathrm{TM}} 11$ Package, Invitrogen Dynal AS). RNA secondary structure predictions were performed using mFold version 2.3 with the eighty ultimate $5{ }^{\prime}$ and $3^{\prime}$ - nucleotides of the mRNAs from each segment as input sequence (http://mfold.rna.albany.edu/?q = mfold/RNAFolding-Form2.3) [35]. Default parameters were used in the predictions except for temperature, which was set to $15^{\circ} \mathrm{C}$. PSIPRED v3.0 was used for predictions of protein secondary structures (http://bioinf.cs.ucl.ac.uk/psipred/). BindN was used to predict putative RNA binding properties of the proteins (http:// bioinfo.ggc.org/bindn/) [59]. The NetNES 1.1 server was used to predict putative leucine-rich nuclear export signals (NESs) in the proteins (http://www.cbs.dtu.dk/services/NetNES/) [105]. Multicoil and COILS were used to predict the presence of putative coiled coil regions in proteins (http://groups.csail.mit.edu/cb/ multicoil/cgi-bin/multicoil.cgi, http://embnet.vital-it.ch/ software/COILS_form.html) [147,148]. Default settings were used in the predictions except for Multicoil were window size of 21 was used. Prediction of theoretical molecular weights and isoelectric points (pI's) for putative PRV proteins was performed using the Compute pI/Mw tool available at http://web.expasy. org/compute_pi/. The presence of putative nuclear localization signals (NLS) in PRV proteins was investigated using PSORTII available at http://psort.hgc.jp/form2.html. Prediction of $\mathrm{N}$ terminal myristoylation was performed using the tools available at http://web.expasy.org/myristoylator/and http://mendel.imp. ac.at/myristate/SUPLpredictor.htm. ProtScale, available at http://web.expasy.org/protscale/with the algorithm by Kyte and Doolittle [149], was used to generate hydrophobicity plots for hypothetical PRV proteins encoded by accessory ORFs and the FAST proteins from ARV-138 and GCRV-873. Prediction of S-palmitoylation sites was performed using CSS-Palm 3.0 using the highest threshold setting [150]. Putative N-glycosylation sites in PRV proteins was predicted using the NetNglyc 1.1 server available at http://www.cbs.dtu.dk/services/NetNGlyc/.

\section{Cloning, Transfection and Immunofluorescence Staining}

The samples were collected from fish originating from a natural outbreak of heart and skeletal muscle inflammation (HSMI) in a commercial Atlantic salmon fish farm (MH-050607). The fish were dead, caused by HSMI, when samples were taken. Thus no approval from Institutional Animal Care and Use Committee (IACUC) or ethics committee was necessary. No experiments that involved fish were performed. The PRV 03 ORF was amplified by RT-PCR from heart/kidney tissue of HSMI-diseased fish, cloned into the pET-100 plasmid vector and expressed in E. coli according to the manufacturer's instructions (Invitrogen). Proteins were purified from SDS-PAGE gels and used to raise PRV $\sigma 3$ specific polyclonal anti-serum in rabbits. Antibody specificity was confirmed in western blot. The anti-p13 was produced by immunization of one rabbit with $0.5 \mathrm{mg}$ Keyhole limpet hemocyanin (KLH) peptide, p13 ORF aa104-113, per injection (GenScript Corp, Piscataway, NJ). For both antigens the primary immunization was administered with Freund's complete adjuvant and the following with Freund's incomplete adjuvant. Antibody specificity to the KLH peptide was confirmed in a dot blot. The PRV $\sigma 3$ and the p13 ORFs were also cloned in the pcDNA3.1 vector for expression in eukaryotic cells. VERO cells $\left(\mathrm{ATCG}^{\circledR} \mathrm{CCL}-81^{\mathrm{TM}}\right.$ ) grown at $37^{\circ} \mathrm{C}$ were plated on $0.17 \mathrm{~mm}$ cover slips in 24 well plates $\left(1 \times 10^{5}\right.$ cells/well $)$, and transfected the following day in $500 \mu \mathrm{l}$ Opti-MEM (Invitrogen) added a mixture of $2 \mu \mathrm{g}$ expression plasmid and $4 \mu \mathrm{l}$ of Xtremegene transfection reagent (Roche). Chinook salmon embryo (CHSE-214) cells
(Sigma-Aldrich) grown at $20^{\circ} \mathrm{C}$ were transfected using an Amaxa Nucleofector I Device (Lonza). Three million cells were diluted in $100 \mu \mathrm{l}$ Ingenio Electroporation Solution (Mirus), added $5 \mu \mathrm{g}$ expression plasmid and transfected using the Amaxa T-20 program, followed by plating on $0.17 \mathrm{~mm}$ cover slips in 24 well plates. VERO cells were incubated for $24 \mathrm{~h}$ and CHSE cells for $72 \mathrm{~h}$, after which cells were fixed in $4 \%$ formaldehyde and treated with $5 \mu \mathrm{g} / \mathrm{ml}$ Wheat Germ Agglutinin (WGA) Alexa Fluor 555 conjugate (Molecular Probes). Cell were washed with Hank's balanced salt solution (HBSS) (Sigma-Aldrich) and permeabilized with BD Cytofix/Cytoperm (BD Biosciences Pharmingen, CA, USA). Primary antiserum anti- $\sigma 3(1: 1000)$ or anti-p13 (1:1000) was added, followed by secondary antibody Alexa Fluor 488conjugated anti-rabbit IgG (1:500) (Molecular Probes). Subsequent wash steps were performed with BD Perm/Wash solution (BD Biosciences Pharmingen). The cover slips were mounted using ProLong Gold antifade mounting media containing DAPI for nuclear staining (Molecular Probes), and cells were visualized on a Zeiss LSM710 confocal microscope (Zeiss, Jena, Germany). The fluorochromes DAPI, Alexa Fluor 488 and Alexa Fluor 555 were excited by lasers at $405 \mathrm{~nm}, 488 \mathrm{~nm}$ and $561 \mathrm{~nm}$, respectively.

\section{Supporting Information}

Figure S1 Multiple sequence alignment of PRV L1 ORF ( $\lambda 3)$ with corresponding ORFs from the reovirus prototype strains MRV T3D, ARV-138 and GCRV-873. RNAdependent RNA polymerase ( $\mathrm{RdRp}$ ) domains are indicated with the universally conserved GDD domain (in Motif III) boxed.

(TIF)

Figure S2 Multiple sequence alignment of PRV L2 ORF ( $\lambda 2)$ with guanylyltransferases from the reovirus prototype strains MRV T3D, ARV-138 and GGRV-873. * = lysine residues in MRV essential $\left(\mathbf{K}_{190}\right)$ or significant contributor $\left(\mathbf{K}_{171}\right)$ for autoguanylation in the MRV, ARV and GCRV proteins, $\boldsymbol{\Delta}=$ conserved histidines essential for guanylyltransferase activity in the MRV protein, $\mathbf{\square}=\mathrm{ATP} / \mathrm{GTP}$ binding site motif $\mathrm{A}$ in ARV, boxed $=S$-adenosyl-L-methionine $(\mathrm{SAM})$ binding pocket, - = ATP/GTP binding site motif A in MRV, and $\downarrow=$ hypersensitive cleavage site in recombinant MRV $\lambda 2$ and ARV $1733 \lambda \mathrm{C}$. (TIF)

Figure S3 Multiple sequence alignment of PRV L3 ORF $(\lambda 1)$ with the helicase-NTPase/core capsid shell proteins from the reovirus prototype strains MRV T3D, ARV-138 and GCRV-873. * = conserved $\mathrm{CCHH}$ zinc-finger motif.

(TIF)

Figure S4 Multiple sequence alignment of PRV M1 ORF encoding the $\mu 2$ protein with the homologues proteins from the reovirus prototype strains MRV T3D, ARV-138 and GGRV-873. $\boldsymbol{\Delta}=$ conserved proline residue suggested to play a key role in the formation and structural organisation of reovirus inclusion bodies, a determinant of type I IFN antagonism

and a modulator of myocarditis in neonatal mice. $\bullet=$ leucine vs. phenylananine, a determinant of tissue tropism of MRV $\mu 2$ in MDCK cells. $\mathbf{\square}=$ possible NLS in MRV. Red lines = nucleotide binding/triphosphate phosphohydrolase regions, and * = conserved lysine residues essential for ATPase activity in ARV $\mu$ A. A nuclear export signal (NES) has been predicted for MRV $\mu 2$ (residues 328-335) [151]. NetNES 1.1 predicts a NES in ARV $\mu \mathrm{A}$ in the same region, while in GCRV, $\mathrm{L}_{233}, \mathrm{~L}_{238}$ and $\mathrm{L}_{607}$ are predicted to participate in a NES, and in PRV $\mathrm{L}_{80}$ (numbering 
according to the GCRV and PRV sequences, respectively) (not shown).

(TIF)

Figure S5 Multiple sequence alignment of PRV M2 ORF encoding the $\mu 1 / \mu$ B major outer capsid protein with the homologues proteins from the reovirus prototype strains MRV T3D, ARV-138 and GGRV-873. * = myristoylation site in the MRV protein. $\downarrow=$ post-translational cleavage site producing $\mathrm{N}$ - and $\mathrm{C}$-terminal fragment $\mu 1 \mathrm{~N}$ and $\mu 1 \mathrm{C}$ (MRV) or $\mu \mathrm{BN}$ and $\mu \mathrm{BC}(\mathrm{ARV})$. The $\mathrm{C}$-terminal end of the MRV protein is extended by 33 amino acids compared to the homologous proteins in ARV and GCRV. The PRV protein is also extended, by 28 amino acids.

(TIF)

Figure S6 Multiple sequence alignment of PRV M3 ORF encoding the putative $\mu$ NS protein aligned with $\mu$ NS/ NS80 proteins from the reovirus prototype strains MRV T3D, ARV-138 and GGRV-873. $\downarrow=$ N-terminal end of second translation product of MRV $(\mu \mathrm{NSC})$. Met-57, conserved in MRV and PRV is boxed red. $*=$ conserved putative zinc-hook motif crucial in the formation of inclusion-like structures in the MRV protein $[86,90,152]$. Black lines indicate sequence regions with higher level of conservation with the motif XGXDPX being boxed. In $\mathrm{ARV}$, the larger region forms part of a region that has been shown to be involved in inclusion maturation [86]. Grey solid and dotted lines $=$ coil-coil $(\mathrm{s})$ regions as predicted by MultiCoil (window size: 21, probability cutoff: 0,5). The MRV $\mathrm{L}_{711} \mathrm{IDFS}_{715}$ motif shown to be required for the recruitment of clathrin to viral factories is boxed red.

(TIF)

Figure S7 Multiple sequence alignment of PRV S1 ORF encoding the major outer capsid $\sigma 3$ protein with the homologues proteins from the reovirus prototype strains MRV T3D, ARV-138 and GGRV-873. * = conserved Zn-finger motif.

(TIF)

Figure S8 Multiple sequence alignment of PRV S2 ORF encoding the inner capsid $\sigma 2$ protein with the homologues proteins from the reovirus prototype strains MRV T3D $\boldsymbol{\sigma} 2, \mathbf{A R V} \boldsymbol{\sigma A}$ and GGRV-873 VP6. $*=\mathrm{R}_{273}$, one of

\section{References}

1. Palacios G, Løvoll M, Tengs T, Hornig M, Hutchison S, et al. (2010) Heart and skeletal muscle inflammation of farmed salmon is associated with infection with a novel reovirus. PLoS One 5: el1487.

2. Kongtorp RT, Taksdal T, Lyngøy A (2004) Pathology of heart and skeletal muscle inflammation (HSMI) in farmed Atlantic salmon Salmo salar. Dis Aquat Organ 59: 217-224.

3. Mikalsen AB, Haugland Ø, Rode M, Solbakk IT, Evensen Ø (2012) Atlantic salmon reovirus infection causes a CD8 T cell myocarditis in Atlantic salmon (Salmo salar L.). PLoS One 7: e37269.

4. Løvoll M, Wiik-Nielsen J, Grove S, Wiik-Nielsen CR, Kristoffersen AB, et al. (2010) A novel totivirus and piscine reovirus (PRV) in Atlantic salmon (Salmo salar) with cardiomyopathy syndrome (CMS). Virol J 7: 309

5. Attoui H, Fang Q Mohd JF, Cantaloube JF, Biagini P, et al. (2002) Common evolutionary origin of aquareoviruses and orthoreoviruses revealed by genome characterization of Golden shiner reovirus, Grass carp reovirus, Striped bass reovirus and golden ide reovirus (genus Aquareovirus, family Reoviridae). J Gen Virol 83: 1941-1951.

6. Duncan R (1999) Extensive sequence divergence and phylogenetic relationships between the fusogenic and nonfusogenic orthoreoviruses: a species proposal. Virology 260: 316-328.

7. Thalmann CM, Cummins DM, Yu M, Lunt R, Pritchard LI, et al. (2010) Broome virus, a new fusogenic Orthoreovirus species isolated from an Australian fruit bat. Virology 402: 26-40.

8. Weiner HL, Drayna D, Averill DR Jr, Fields BN (1977) Molecular basis of reovirus virulence: role of the S1 gene. Proc Natl Acad Sci U S A 74: 5744 5748. two arginines in ARV $\sigma$ A linked to dsRNA binding and nucleolar localization, conserved in fusogenic orthoreoviruses.

(TIF)

Figure S9 Multiple sequence alignment of PRV S3 ORF encoding the putative $\sigma \mathrm{NS}$ protein aligned with $\sigma \mathrm{NS} /$ NS38 proteins from reovirus prototype strains MRV T3D, ARV-138 and GGRV-873. Solid black lines represent sequence regions of higher conservation containing putative nuclear export signals.

(TIF)

Figure S10 GOILS prediction of coiled coil regions in PRV $\sigma 1$ compared to that of the reovirus prototype strains MRV T3D, ARV-138 and GGRV-873. X-axis displays amino acid positions and the $\mathrm{y}$-axis probabilities.

(TIF)

Figure S11 Hydrophobic characters of the hypothetical PRV proteins $p 11$ and 88 as predicted by ProtScale compared to the FAST proteins from ARV-138 and GGRV-873. Predictions were performed using the algorithm by Kyte and Doolittle [149] averaged over a window of nine residues. Positive- and negative scores indicate hydrophobic- and hydrophilic amino acids, respectively. $\mathrm{TM}=$ transmembrane domains, $\mathrm{PB}=$ polybasic regions and $\mathrm{HP}=$ Hydrophobic patch .

(TIF)

Table S1 Genbank accession numbers for reovirus nucleotide sequences used in the study.

(DOCX)

\section{Acknowledgments}

We thank Ingvild Berg Nyman for assistance in subcloning work and Even Thoen for assistance with confocal microscopy.

\section{Author Contributions}

Conceived and designed the experiments: TM MKD TT ML ØWF CRW SG SL BR ER. Performed the experiments: TM MKD TT ML ØWF CRW SL. Analyzed the data: TM MKD TT ØWF SL ER. Contributed reagents/materials/analysis tools: TM MKD TT ML ØWF CRW SL. Wrote the paper: TM MKD TT ØWF SL ER.

9. Weiner HL, Powers ML, Fields BN (1980) Absolute linkage of virulence and central nervous system cell tropism of reoviruses to viral hemagglutinin. J Infect Dis 141: 609-616.

10. Lee PW, Hayes EC, Joklik WK (1981) Protein sigma 1 is the reovirus cell attachment protein. Virology 108: 156-163.

11. Tyler KL, Mann MA, Fields BN, Virgin HW (1993) Protective anti-reovirus monoclonal antibodies and their effects on viral pathogenesis. J Virol 67: 34463453.

12. Silverstein SC, Astell C, Levin DH, Schonberg M, Acs G (1972) The mechanisms of reovirus uncoating and gene activation in vivo. Virology 47 : 797-806

13. Chang CT, Zweerink HJ (1971) Fate of parental reovirus in infected cell. Virology 46: 544-555.

14. Lucia-Jandris P, Hooper JW, Fields BN (1993) Reovirus M2 gene is associated with chromium release from mouse L cells. J Virol 67: 5339-5345.

15. Chandran K, Walker SB, Chen Y, Contreras CM, Schiff LA, et al. (1999) In vitro recoating of reovirus cores with baculovirus-expressed outer-capsid proteins mul and sigma3. J Virol 73: 3941-3950.

16. Sturzenbecker LJ, Nibert M, Furlong D, Fields BN (1987) Intracellular digestion of reovirus particles requires a low $\mathrm{pH}$ and is an essential step in the viral infectious cycle. J Virol 61: 2351-2361.

17. Chandran K, Farsetta DL, Nibert ML (2002) Strategy for nonenveloped virus entry: a hydrophobic conformer of the reovirus membrane penetration protein micro 1 mediates membrane disruption. J Virol 76: 9920-9933.

18. Chandran K, Nibert ML (2003) Animal cell invasion by a large nonenveloped virus: reovirus delivers the goods. Trends Microbiol 11: 374-382. 
19. Guglielmi KM, Johnson EM, Stehle T, Dermody TS (2006) Attachment and cell entry of mammalian orthoreovirus. Curr Top Microbiol Immunol 309: 138.

20. Furuichi Y, Muthukrishnan S, Tomasz J, Shatkin AJ (1976) Mechanism of formation of reovirus mRNA 5 '-terminal blocked and methylated sequence, $\mathrm{m}^{7} \mathrm{GpppG} \mathrm{m}^{\mathrm{m}} \mathrm{pC}$. J Biol Chem 251: 5043-5053.

21. Bisaillon M, Bergeron J, Lemay G (1997) Characterization of the nucleoside triphosphate phosphohydrolase and helicase activities of the reovirus lambdal protein. J Biol Chem 272: 18298-18303.

22. Bisaillon M, Lemay $\mathrm{G}$ (1997) Characterization of the reovirus lambdal protein RNA 5'-triphosphatase activity. J Biol Chem 272: 29954-29957.

23. Noble S, Nibert ML (1997) Characterization of an ATPase activity in reovirus cores and its genetic association with core-shell protein lambdal. J Virol 71: 2182-2191.

24. Cleveland DR, Zarbl H, Millward S (1986) Reovirus guanylyltransferase is L2 gene product lambda 2. J Virol 60: 307-311.

25. Wiener JR, Joklik WK (1989) The sequences of the reovirus serotype 1, 2, and $3 \mathrm{~L} 1$ genome segments and analysis of the mode of divergence of the reovirus serotypes. Virology 169: 194-203.

26. Furuichi Y, Morgan M, Muthukrishnan S, Shatkin AJ (1975) Reovirus messenger RNA contains a methylated, blocked $5^{\prime}$-terminal structure: $\mathrm{m}^{7} \mathrm{G}\left(5^{\prime}\right) \operatorname{ppp}\left(5^{\prime}\right) \mathrm{G}^{\mathrm{m}} \mathrm{pCp}$-. Proc Natl Acad Sci U S A 72: 362-366.

27. Fausnaugh J, Shatkin AJ (1990) Active site localization in a viral mRNA capping enzyme. J Biol Chem 265: 7669-7672.

28. Mao ZX, Joklik WK (1991) Isolation and enzymatic characterization of protein lambda 2, the reovirus guanylyltransferase. Virology 185: 377-386.

29. Martinez-Costas J, Varela R, Benavente J (1995) Endogenous enzymatic activities of the avian reovirus S1133: identification of the viral capping enzyme. Virology 206: 1017-1026.

30. Schiff LA, Nibert ML, Tyler KL (2007) Orthoreoviruses and their replication. In: Knipe DM, Howley PM, Griffin DE, Lamb RA, Martin MA et al., editors. Fields Virology. 5 ed: Lippincott Williams \& Wilkins, Philadelphia, PA. 18531915.

31. Mohd JF, Goodwin AE, Belhouchet M, Merry G, Fang Q, et al. (2008) Complete characterisation of the American grass carp reovirus genome (genus Aquareovirus: family Reoviridae) reveals an evolutionary link between aquareoviruses and coltiviruses. Virology 373: 310-321.

32. Chapell JD, Goral MI, Rodgers SE, dePamphilis CW, Dermody TS (1994) Sequence diversity within the reovirus $\mathrm{S} 2$ gene: reovirus genes reassort in nature, and their termini are predicted to form a panhandle motif. J Virol 68: $750-756$.

33. Li JK, Keene JD, Scheible PP, Joklik WK (1980) Nature of the 3 '-terminal sequences of the plus and minus strands of the $\mathrm{S} 1$ gene of reovirus serotypes 1 , 2 and 3. Virology 105: 41-51.

34. Zou S, Brown EG (1992) Identification of sequence elements containing signals for replication and encapsidation of the reovirus M1 genome segment. Virology 186: 377-388.

35. Zuker M (2003) Mfold web server for nucleic acid folding and hybridization prediction. Nucleic Acids Res 31: 3406-3415.

36. Tao Y, Farsetta DL, Nibert ML, Harrison SC (2002) RNA synthesis in a cagestructural studies of reovirus polymerase lambda3. Cell 111: 733-745.

37. Bisaillon M, Lemay G (1999) Computational sequence analysis of mammalian reovirus proteins. Virus Genes 18: 13-37.

38. Xu W, Coombs KM (2008) Avian reovirus L2 genome segment sequences and predicted structure/function of the encoded RNA-dependent RNA polymerase protein. Virol J 5: 153.

39. Bruenn JA (2003) A structural and primary sequence comparison of the viral RNA-dependent RNA polymerases. Nucleic Acids Res 31: 1821-1829.

40. O'Reilly EK, Kao CC (1998) Analysis of RNA-dependent RNA polymerase structure and function as guided by known polymerase structures and computer predictions of secondary structure. Virology 252: 287-303.

41. Kamer G, Argos P (1984) Primary structural comparison of RNA-dependent polymerases from plant, animal and bacterial viruses. Nucleic Acids Res 12: 7269-7282.

42. Poch O, Sauvaget I, Delarue M, Tordo N (1989) Identification of four conserved motifs among the RNA-dependent polymerase encoding elements. EMBO J 8: 3867-3874.

43. Morozov SY (1989) A possible relationship of reovirus putative RNA polymerase to polymerases of positive-strand RNA viruses. Nucleic Acids Res 17: 5394 .

44. Hsiao J, Martinez-Costas J, Benavente J, Vakharia VN (2002) Cloning, expression, and characterization of avian reovirus guanylyltransferase. Virology 296: 288-299.

45. Luongo CL, Contreras CM, Farsetta DL, Nibert ML (1998) Binding site for Sadenosyl-L-methionine in a central region of mammalian reovirus lambda2 protein. Evidence for activities in mRNA cap methylation. J Biol Chem 273: 23773-23780.

46. Luongo CL, Reinisch KM, Harrison SC, Nibert ML (2000) Identification of the guanylyltransferase region and active site in reovirus mRNA capping protein lambda2. J Biol Chem 275: 2804-2810.

47. Qiu T, Luongo CL (2003) Identification of two histidines necessary for reovirus mRNA guanylyltransferase activity. Virology 316: 313-324.
48. Buchan DW, Ward SM, Lobley AE, Nugent TC, Bryson K, et al. (2010) Protein annotation and modelling servers at University College London. Nucleic Acids Res 38: W563-W568.

49. Jones DT (1999) Protein secondary structure prediction based on positionspecific scoring matrices. J Mol Biol 292: 195-202.

50. Varela R, Benavente J (1994) Protein coding assignment of avian reovirus strain S1133. J Virol 68: 6775-6777.

51. Bartlett JA, Joklik WK (1988) The sequence of the reovirus serotype 3 L3 genome segment which encodes the major core protein lambda 1. Virology 167: 31-37.

52. Fang Q Attoui H, Cantaloube JF, Biagini P, Zhu Z, et al. (2000) Sequence of genome segments 1, 2, and 3 of the grass carp reovirus (Genus Aquareovirus, family Reoviridae). Biochem Biophys Res Commun 274: 762-766.

53. Kim J, Tao Y, Reinisch KM, Harrison SC, Nibert ML (2004) Orthoreovirus and Aquareovirus core proteins: conserved enzymatic surfaces, but not proteinprotein interfaces. Virus Res 101: 15-28.

54. Reinisch KM, Nibert ML, Harrison SC (2000) Structure of the reovirus core at 3.6 A resolution. Nature 404: 960-967.

55. Bisaillon M, Lemay G (1997) Molecular dissection of the reovirus lambdal protein nucleic acids binding site. Virus Res 51: 231-237.

56. Harrison SJ, Farsetta DL, Kim J, Noble S, Broering TJ, et al. (1999) Mammalian reovirus L3 gene sequences and evidence for a distinct aminoterminal region of the lambdal protein. Virology 258: 54-64.

57. Lemay G, Danis C (1994) Reovirus lambda 1 protein: affinity for doublestranded nucleic acids by a small amino-terminal region of the protein independent from the zinc finger motif. J Gen Virol 75: 3261-3266.

58. Xu W, Coombs KM (2009) Conserved structure/function of the orthoreovirus major core proteins. Virus Res 144: 44-57.

59. Wang L, Brown SJ (2006) BindN: a web-based tool for efficient prediction of DNA and RNA binding sites in amino acid sequences. Nucleic Acids Res 34: W243-W248.

60. Coombs KM (1998) Stoichiometry of reovirus structural proteins in virus, ISVP, and core particles. Virology 243: 218-228.

61. Brentano L, Noah DL, Brown EG, Sherry B (1998) The reovirus protein mu2, encoded by the M1 gene, is an RNA-binding protein. J Virol 72: 8354-8357.

62. Noble S, Nibert ML (1997) Core protein mu2 is a second determinant of nucleoside triphosphatase activities by reovirus cores. J Virol 71: 7728-7735.

63. Kim J, Parker JS, Murray KE, Nibert ML (2004) Nucleoside and RNA triphosphatase activities of orthoreovirus transcriptase cofactor mu2. J Biol Chem 279: 4394-4403.

64. Su YP, Shien JH, Liu HJ, Yin HS, Lee LH (2007) Avian reovirus core protein muA expressed in Escherichia coli possesses both NTPase and RTPase activities. J Gen Virol 88: 1797-1805.

65. Kobayashi T, Ooms LS, Chappell JD, Dermody TS (2009) Identification of functional domains in reovirus replication proteins muNS and mu2. J Virol 83: 2892-2906.

66. Parker JS, Broering TJ, Kim J, Higgins DE, Nibert ML (2002) Reovirus core protein mu2 determines the filamentous morphology of viral inclusion bodies by interacting with and stabilizing microtubules. J Virol 76: 4483-4496.

67. Yin P, Keirstead ND, Broering TJ, Arnold MM, Parker JS, et al. (2004) Comparisons of the M1 genome segments and encoded mu2 proteins of different reovirus isolates. Virol J 1: 6.

68. Touris-Otero F, Cortez-San MM, Martinez-Costas J, Benavente J (2004) Avian reovirus morphogenesis occurs within viral factories and begins with the selective recruitment of sigmaNS and lambdaA to microNS inclusions. J Mol Biol 341: 361-374.

69. Irvin SC, Zurney J, Ooms LS, Chappell JD, Dermody TS, et al. (2012) A single-amino-acid polymorphism in reovirus protein mu2 determines repression of interferon signaling and modulates myocarditis. J Virol 86: 2302-2311.

70. Jayasuriya AK, Nibert ML, Fields BN (1988) Complete nucleotide sequence of the M2 gene segment of reovirus type 3 dearing and analysis of its protein product mu 1. Virology 163: 591-602.

71. Wiener JR, Joklik WK (1988) Evolution of reovirus genes: a comparison of serotype 1, 2, and $3 \mathrm{M} 2$ genome segments, which encode the major structural capsid protein mu 1C. Virology 163: 603-613.

72. Tillotson L, Shatkin AJ (1992) Reovirus polypeptide sigma 3 and N-terminal myristoylation of polypeptide mu 1 are required for site-specific cleavage to mu 1C in transfected cells. J Virol 66: 2180-2186.

73. Varela R, Martinez-Costas J, Mallo M, Benavente J (1996) Intracellular posttranslational modifications of S1133 avian reovirus proteins. J Virol 70: $2974-2981$

74. Odegard AL, Chandran K, Zhang X, Parker JS, Baker TS, et al. (2004) Putative autocleavage of outer capsid protein microl, allowing release of myristoylated peptide microlN during particle uncoating, is critical for cell entry by reovirus. J Virol 78: 8732-8745.

75. Nibert ML, Odegard AL, Agosto MA, Chandran K, Schiff LA (2005) Putative autocleavage of reovirus mul protein in concert with outer-capsid disassembly and activation for membrane permeabilization. J Mol Biol 345: 461-474.

76. McCrae MA, Joklik WK (1978) The nature of the polypeptide encoded by each of the 10 double-stranded RNA segments of reovirus type 3. Virology 89: 578593.

77. Mustoe TA, Ramig RF, Sharpe AH, Fields BN (1978) Genetics of reovirus: identification of the ds RNA segments encoding the polypeptides of the mu and sigma size classes. Virology 89: 594-604. 
78. Noad L, Shou J, Coombs KM, Duncan R (2006) Sequences of avian reovirus M1, M2 and M3 genes and predicted structure/function of the encoded mu proteins. Virus Res 116: 45-57.

79. Ivanovic T, Boulant S, Ehrlich M, Demidenko AA, Arnold MM, et al. (2011) Recruitment of cellular clathrin to viral factories and disruption of clathrindependent trafficking. Traffic 12: 1179-1195.

80. Mora M, Partin K, Bhatia M, Partin J, Carter C (1987) Association of reovirus proteins with the structural matrix of infected cells. Virology 159: 265-277.

81. Broering TJ, Kim J, Miller CL, Piggott CD, Dinoso JB, et al. (2004) Reovirus nonstructural protein mu NS recruits viral core surface proteins and entering core particles to factory-like inclusions. J Virol 78: 1882-1892.

82. Broering TJ, McCutcheon AM, Centonze VE, Nibert ML (2000) Reovirus nonstructural protein muNS binds to core particles but does not inhibit their transcription and capping activities. J Virol 74: 5516-5524.

83. Broering TJ, Parker JS, Joyce PL, Kim J, Nibert ML (2002) Mammalian reovirus nonstructural protein microNS forms large inclusions and colocalizes with reovirus microtubule-associated protein micro2 in transfected cells. J Virol 76: 8285-8297.

84. Miller CL, Arnold MM, Broering TJ, Hastings CE, Nibert ML (2010) Localization of mammalian orthoreovirus proteins to cytoplasmic factory-like structures via nonoverlapping regions of microNS. J Virol 84: 867-882.

85. Miller CL, Broering TJ, Parker JS, Arnold MM, Nibert ML (2003) Reovirus sigma NS protein localizes to inclusions through an association requiring the mu NS amino terminus. J Virol 77: 4566-4576.

86. Brandariz-Nunez A, Menaya-Vargas R, Benavente J, Martinez-Costas J (2010) Avian reovirus microNS protein forms homo-oligomeric inclusions in a microtubule-independent fashion, which involves specific regions of its Cterminal domain. J Virol 84: 4289-4301.

87. Touris-Otero F, Martinez-Costas J, Vakharia VN, Benavente J (2004) Avian reovirus nonstructural protein microNS forms viroplasm-like inclusions and recruits protein sigmaNS to these structures. Virology 319: 94-106.

88. McCutcheon AM, Broering TJ, Nibert ML (1999) Mammalian reovirus M3 gene sequences and conservation of coiled-coil motifs near the carboxyl terminus of the microNS protein. Virology 264: 16-24.

89. Cai L, Sun X, Shao L, Fang Q (2011) Functional investigation of grass carp reovirus nonstructural protein NS80. Virol J 8: 168.

90. Broering TJ, Arnold MM, Miller CL, Hurt JA, Joyce PL, et al. (2005) Carboxyl-proximal regions of reovirus nonstructural protein muNS necessary and sufficient for forming factory-like inclusions. J Virol 79: 6194-6206.

91. Wiener JR, Bartlett JA, Joklik WK (1989) The sequences of reovirus serotype 3 genome segments M1 and M3 encoding the minor protein mu 2 and the major nonstructural protein mu NS, respectively. Virology 169: 293-304.

92. Busch LK, Rodriguez-Grille J, Casal JI, Martinez-Costas J, Benavente J (2011) Avian and mammalian reoviruses use different molecular mechanisms to synthesize their \{micro\}NS isoforms. J Gen Virol 92: 2566-2574.

93. Kozak M (1991) An analysis of vertebrate mRNA sequences: intimations of translational control. J Cell Biol 115: 887-903.

94. Schnitzer TJ, Ramos T, Gouvea V (1982) Avian reovirus polypeptides: analysis of intracellular virus-specified products, virions, top component, and cores. J Virol 43: 1006-1014.

95. Yin HS, Shieh HK, Lee LH (1997) Characterization of the double-stranded RNA genome segment S3 of avian reovirus. J Virol Methods 67: 93-101.

96. Key T, Read J, Nibert ML, Duncan R (2013) Piscine Reovirus Encodes a Cytotoxic, Nonfusogenic, Integral Membrane Protein and Previously Unrecognized Virion Outer-Capsid Proteins. J Gen Virol 94: 1039-50.

97. Schiff LA, Nibert ML, Co MS, Brown EG, Fields BN (1988) Distinct binding sites for zinc and double-stranded RNA in the reovirus outer capsid protein sigma 3. Mol Cell Biol 8: 273-283.

98. Martinez-Costas J, Grande A, Varela R, Garcia-Martinez C, Benavente J (1997) Protein architecture of avian reovirus S1 133 and identification of the cell attachment protein. J Virol 71: 59-64.

99. Cheng L, Fang Q, Shah S, Atanasov IC, Zhou ZH (2008) Subnanometerresolution structures of the grass carp reovirus core and virion. J Mol Biol 382: 213-222.

100. Guardado-Calvo P, Vazquez-Iglesias L, Martinez-Costas J, Llamas-Saiz AL, Schoehn G, et al. (2008) Crystal structure of the avian reovirus inner capsid protein sigmaA. J Virol 82: 11208-11216.

101. Yin HS, Shien JH, Lee LH (2000) Synthesis in Escherichia coli of avian reovirus core protein varsigmaA and its dsRNA-binding activity. Virology 266: 33-41.

102. Dermody TS, Schiff LA, Nibert ML, Coombs KM, Fields BN (1991) The S2 gene nucleotide sequences of prototype strains of the three reovirus serotypes: characterization of reovirus core protein sigma 2. J Virol 65: 5721-5731.

103. Richardson MA, Furuichi Y (1983) Nucleotide sequence of reovirus genome segment S3, encoding non-structural protein sigma NS. Nucleic Acids Res 11: 6399-6408.

104. Gillian AL, Nibert ML (1998) Amino terminus of reovirus nonstructural protein sigma NS is important for ssRNA binding and nucleoprotein complex formation. Virology 240: 1-11.

105. la Cour T, Kiemer L, Molgaard A, Gupta R, Skriver K, et al. (2004) Analysis and prediction of leucine-rich nuclear export signals. Protein Eng Des Sel 17: $527-536$.
106. Weiner HL, Ault KA, Fields BN (1980) Interaction of reovirus with cell surface receptors. I. Murine and human lymphocytes have a receptor for the hemagglutinin of reovirus type 3. J Immunol 124: 2143-2148.

107. Ernst H, Shatkin AJ (1985) Reovirus hemagglutinin mRNA codes for two polypeptides in overlapping reading frames. Proc Natl Acad Sci U S A 82: 4852.

108. Bodelon G, Labrada L, Martinez-Costas J, Benavente J (2001) The avian reovirus genome segment $\mathrm{S} 1$ is a functionally tricistronic gene that expresses one structural and two nonstructural proteins in infected cells. Virology 290: $181-191$

109. Grande A, Costas C, Benavente J (2002) Subunit composition and conformational stability of the oligomeric form of the avian reovirus cellattachment protein sigmaC. J Gen Virol 83: 131-139.

110. Shaw AL, Samal SK, Subramanian K, Prasad BV (1996) The structure of aquareovirus shows how the different geometries of the two layers of the capsid are reconciled to provide symmetrical interactions and stabilization. Structure 4: 957-967.

111. Fraser RD, Furlong DB, Trus BL, Nibert ML, Fields BN, et al. (1990) Molecular structure of the cell-attachment protein of reovirus: correlation of computer-processed electron micrographs with sequence-based predictions. J Virol 64: 2990-3000.

112. Nibert ML, Dermody TS, Fields BN (1990) Structure of the reovirus cellattachment protein: a model for the domain organization of sigma 1.J Virol 64: 2976-2989.

113. Shapouri MR, Kane M, Letarte M, Bergeron J, Arella M, et al. (1995) Cloning, sequencing and expression of the $\mathrm{S} 1$ gene of avian reovirus. J Gen Virol 76: 1515-1520.

114. Strong JE, Leone G, Duncan R, Sharma RK, Lee PW (1991) Biochemical and biophysical characterization of the reovirus cell attachment protein sigma 1: evidence that it is a homotrimer. Virology 184: 23-32.

115. Barton ES, Forrest JC, Connolly JL, Chappell JD, Liu Y, et al. (2001) Junction adhesion molecule is a receptor for reovirus. Cell 104: 441-451.

116. Dryden KA, Wang G, Yeager M, Nibert ML, Coombs KM, et al. (1993) Early steps in reovirus infection are associated with dramatic changes in supramolecular structure and protein conformation: analysis of virions and subviral particles by cryoelectron microscopy and image reconstruction. J Cell Biol 122: 1023-1041.

117. Chappell JD, Duong JL, Wright BW, Dermody TS (2000) Identification of carbohydrate-binding domains in the attachment proteins of type 1 and type 3 reoviruses. J Virol 74: 8472-8479.

118. Chappell JD, Prota AE, Dermody TS, Stehle T (2002) Crystal structure of reovirus attachment protein sigmal reveals evolutionary relationship to adenovirus fiber. EMBO J 21: 1-11.

119. Campbell JA, Schelling P, Wetzel JD, Johnson EM, Forrest JC, et al. (2005) Junctional adhesion molecule a serves as a receptor for prototype and fieldisolate strains of mammalian reovirus. J Virol 79: 7967-7978.

120. Gentsch JR, Pacitti AF (1985) Effect of neuraminidase treatment of cells and effect of soluble glycoproteins on type 3 reovirus attachment to murine L cells. J Virol 56: 356-364.

121. Paul RW, Choi AH, Lee PW (1989) The alpha-anomeric form of sialic acid is the minimal receptor determinant recognized by reovirus. Virology 172: $382-$ 385 .

122. Dermody TS, Nibert ML, Bassel-Duby R, Fields BN (1990) A sigma 1 region important for hemagglutination by serotype 3 reovirus strains. J Virol 64: 5173-5176.

123. Chappell JD, Gunn VL, Wetzel JD, Baer GS, Dermody TS (1997) Mutations in type 3 reovirus that determine binding to sialic acid are contained in the fibrous tail domain of viral attachment protein sigmal. J Virol 71: 1834-1841.

124. Reiter DM, Frierson JM, Halvorson EE, Kobayashi T, Dermody TS, et al. (2011) Crystal structure of reovirus attachment protein sigmal in complex with sialylated oligosaccharides. PLoS Pathog 7: e1002166.

125. Racine T, Hurst T, Barry C, Shou J, Kibenge F, et al. (2009) Aquareovirus effects syncytiogenesis by using a novel member of the FAST protein family translated from a noncanonical translation start site. J Virol 83: 5951-5955.

126. Guo H, Sun X, Yan L, Shao L, Fang Q (2013) The NS16 protein of aquareovirus- $\mathrm{C}$ is a fusion-associated small transmembrane (FAST) protein, and its activity can be enhanced by the nonstructural protein NS26. Virus Res 171: 129-137.

127. Shmulevitz M, Duncan R (2000) A new class of fusion-associated small transmembrane (FAST) proteins encoded by the non-enveloped fusogenic reoviruses. EMBO J 19: 902-912.

128. Ke F, He LB, Pei C, Zhang OY (2011) Turbot reovirus (SMReV) genome encoding a FAST protein with a non-AUG start site. BMC Genomics 12: 323.

129. Dawe S, Duncan R (2002) The S4 genome segment of baboon reovirus is bicistronic and encodes a novel fusion-associated small transmembrane protein. J Virol 76: 2131-2140.

130. Corcoran JA, Duncan R (2004) Reptilian reovirus utilizes a small type III protein with an external myristylated amino terminus to mediate cell-cell fusion. J Virol 78: 4342-4351.

131. Boutilier J, Duncan R (2011) The reovirus fusion-associated small transmembrane (FAST) proteins: virus-encoded cellular fusogens. Curr Top Membr 68: $107-140$. 
132. Touris-Otero F, Martinez-Costas J, Vakharia VN, Benavente J (2005) Characterization of the nucleic acid-binding activity of the avian reovirus non-structural protein sigma NS. J Gen Virol 86: 1159-1169.

133. Zurney J, Kobayashi T, Holm GH, Dermody TS, Sherry B (2009) Reovirus $\mathrm{mu} 2$ protein inhibits interferon signaling through a novel mechanism involving nuclear accumulation of interferon regulatory factor 9. J Virol 83: 2178-2187.

134. Gonzalez-Lopez C, Martinez-Costas J, Esteban M, Benavente J (2003) Evidence that avian reovirus sigmaA protein is an inhibitor of the doublestranded RNA-dependent protein kinase. J Gen Virol 84: 1629-1639.

135. Martinez-Costas J, Gonzalez-Lopez C, Vakharia VN, Benavente J (2000) Possible involvement of the double-stranded RNA-binding core protein sigmaA in the resistance of avian reovirus to interferon. J Virol 74: 1124-1131.

136. Sherry B (2009) Rotavirus and reovirus modulation of the interferon response. J Interferon Cytokine Res 29: 559-567.

137. Imani F, Jacobs BL (1988) Inhibitory activity for the interferon-induced protein kinase is associated with the reovirus serotype 1 sigma 3 protein. Proc Natl Acad Sci U S A 85: 7887-7891.

138. Lauksund S, Svingerud T, Bergan V, Robertsen B (2009) Atlantic salmon IPS1 mediates induction of IFNal and activation of NF-kappaB and localizes to mitochondria. Dev Comp Immunol 33: 1196-1204.

139. Bergan V, Steinsvik S, Xu H, Kileng Ø, Robertsen B (2006) Promoters of type I interferon genes from Atlantic salmon contain two main regulatory regions. FEBS J 273: 3893-3906.

140. Boehme KW, Frierson JM, Konopka JL, Kobayashi T, Dermody TS (2011) The reovirus sigmals protein is a determinant of hematogenous but not neural virus dissemination in mice. J Virol 85: 11781-11790.

141. Boehme KW, Guglielmi KM, Dermody TS (2009) Reovirus nonstructural protein sigmals is required for establishment of viremia and systemic dissemination. Proc Natl Acad Sci U S A 106: 19986-19991.
142. Hoyt CC, Richardson-Burns SM, Goody RJ, Robinson BA, Debiasi RL, et al. (2005) Nonstructural protein sigmals is a determinant of reovirus virulence and influences the kinetics and severity of apoptosis induction in the heart and central nervous system. J Virol 79: 2743-2753.

143. Poggioli GJ, Keefer C, Connolly JL, Dermody TS, Tyler KL (2000) Reovirusinduced $\mathrm{G}(2) / \mathrm{M}$ cell cycle arrest requires sigmals and occurs in the absence of apoptosis. J Virol 74: 9562-9570.

144. Chulu JL, Huang WR, Wang L, Shih WL, Liu HJ (2010) Avian reovirus nonstructural protein p17-induced $\mathrm{G}(2) / \mathrm{M}$ cell cycle arrest and host cellular protein translation shutoff involve activation of p53-dependent pathways. J Virol 84: 7683-7694.

145. Costas C, Martinez-Costas J, Bodelon G, Benavente J (2005) The second open reading frame of the avian reovirus $\mathrm{S} 1$ gene encodes a transcription-dependent and CRM1-independent nucleocytoplasmic shuttling protein. J Virol 79: 2141 2150.

146. John KR, George MR, Richards RH, Frerichs GN (2001) Characteristics of a new reovirus isolated from epizootic ulcerative syndrome infected snakehead fish. Dis Aquat Organ 46: 83-92.

147. Wolf E, Kim PS, Berger B (1997) MultiCoil: a program for predicting two- and three-stranded coiled coils. Protein Sci 6: 1179-1189.

148. Lupas A, Van DM, Stock J (1991) Predicting coiled coils from protein sequences. Science 252: 1162-1164.

149. Kyte J, Doolittle RF (1982) A simple method for displaying the hydropathic character of a protein. J Mol Biol 157: 105-132.

150. Ren J, Wen L, Gao X, Jin C, Xue Y, et al. (2008) CSS-Palm 2.0: an updated software for palmitoylation sites prediction. Protein Eng Des Sel 21: 639-644. 